\title{
MuRF2 regulates PPAR $\gamma 1$ activity to protect against diabetic cardiomyopathy and enhance weight gain induced by a high fat diet
}

Jun He ${ }^{1,2 \dagger}$, Megan T Quintana ${ }^{3 \dagger}$, Jenyth Sullivan ${ }^{4}$, Traci L Parry ${ }^{5}$, Trisha J Grevengoed ${ }^{6}$, Jonathan C Schisler ${ }^{5,7}$, Joseph A Hill ${ }^{8}$, Cecelia C Yates ${ }^{9}$, Rudo F Mapanga ${ }^{10}$, M Faadiel Essop ${ }^{10}$, William E Stansfield ${ }^{3}$, James R Bain ${ }^{11,12}$, Christopher B Newgard ${ }^{11,12}$, Michael J Muehlbauer ${ }^{11}$, Yipin Han ${ }^{13}$, Brian A Clarke ${ }^{14}$ and Monte S Willis $5^{1,5^{*}}$

\begin{abstract}
Background: In diabetes mellitus the morbidity and mortality of cardiovascular disease is increased and represents an important independent mechanism by which heart disease is exacerbated. The pathogenesis of diabetic cardiomyopathy involves the enhanced activation of PPAR transcription factors, including PPAR $\alpha$, and to a lesser degree PPAR $\beta$ and PPAR $\gamma 1$. How these transcription factors are regulated in the heart is largely unknown. Recent studies have described post-translational ubiquitination of PPARs as ways in which PPAR activity is inhibited in cancer. However, specific mechanisms in the heart have not previously been described. Recent studies have implicated the musclespecific ubiquitin ligase muscle ring finger-2 (MuRF2) in inhibiting the nuclear transcription factor SRF. Initial studies of MuRF2-/- hearts revealed enhanced PPAR activity, leading to the hypothesis that MuRF2 regulates PPAR activity by post-translational ubiquitination.

Methods: MuRF2-/- mice were challenged with a 26-week $60 \%$ fat diet designed to simulate obesity-mediated insulin resistance and diabetic cardiomyopathy. Mice were followed by conscious echocardiography, blood glucose, tissue triglyceride, glycogen levels, immunoblot analysis of intracellular signaling, heart and skeletal muscle morphometrics, and PPAR $\alpha$, PPAR $\beta$, and PPAR $\gamma 1$-regulated mRNA expression.

Results: MURF2 protein levels increase $\sim 20 \%$ during the development of diabetic cardiomyopathy induced by high fat diet. Compared to littermate wildtype hearts, MuRF2-/ - hearts exhibit an exaggerated diabetic cardiomyopathy, characterized by an early onset systolic dysfunction, larger left ventricular mass, and higher heart weight. MuRF2-/hearts had significantly increased PPAR $\alpha$ - and PPAR $\gamma 1$-regulated gene expression by RT-qPCR, consistent with MuRF2's regulation of these transcription factors in vivo. Mechanistically, MuRF2 mono-ubiquitinated PPAR $\alpha$ and PPAR 1 in vitro, consistent with its non-degradatory role in diabetic cardiomyopathy. However, increasing MuRF2:PPAR 1 (>5:1) beyond physiological levels drove poly-ubiquitin-mediated degradation of PPAR 1 in vitro, indicating large MuRF2 increases may lead to PPAR degradation if found in other disease states.

Conclusions: Mutations in MuRF2 have been described to contribute to the severity of familial hypertrophic cardiomyopathy. The present study suggests that the lack of MuRF2, as found in these patients, can result in an exaggerated diabetic cardiomyopathy. These studies also identify MURF2 as the first ubiquitin ligase to regulate cardiac PPAR $\alpha$ and PPAR 1 activities in vivo via post-translational modification without degradation.
\end{abstract}

\footnotetext{
*Correspondence: monte_willis@med.unc.edu

†Jun He and Megan T Quintana contributed equally to this work

${ }^{1}$ Department of Pathology and Laboratory Medicine, University of North

Carolina, 111 Mason Farm Road, MBRB 2340B, Chapel Hill, NC, USA

Full list of author information is available at the end of the article
} 
Keywords: MuRF2, Diabetic cardiomyopathy, Post-translational modification, Multi-ubiquitin, PPAR, Ubiquitin ligase

\section{Background}

The leading cause of morbidity and mortality worldwide is cardiovascular disease [1], frequently accompanied by the dysregulation of fatty acid metabolism associated with diabetes mellitus (DM). In the presence of DM, the morbidity and mortality of cardiovascular disease is increased and represents an important independent mechanism by which heart disease is exacerbated $[2,3]$. The characteristic disturbances in myocardial energy and fatty acid homeostasis found in DM are mediated primarily by a network of peroxisome proliferator-activated receptor (PPAR) transcription factors that direct the energy substrates and determine the myocardial homeostasis $[4,5]$. Chronic activation of PPARs in DM leads to an increase in free fatty acid uptake/oxidation corresponding to the level of insulin resistance in cardiomyocytes [6]. The increased reliance on fatty acid metabolism decreases the efficiency of the heart by increasing the amount of oxygen needed to create the needed energy, resulting in lipotoxicity [7]. The ligand (fatty acid)-driven activation of PPAR transcription factors regulate the expression of target genes, which control the uptake, utilization, oxidation, and storage of fatty acids [8]. In the heart, all three PPAR receptors have been identified $(\operatorname{PPAR} \alpha, \operatorname{PPAR} \delta / \beta$, and PPAR $\gamma$ ) and implicated in cardiovascular disease [9].

Insulin resistance is a risk factor for left ventricular (LV) dysfunction and heart failure and is one of the hallmarks of type 2 DM [10]. Despite hyperinsulinemia and hyperglycemia, the diabetic heart relies almost exclusively on fatty acid utilization [11] in both rodent models and humans with excessive fat intake [12]. The resulting increase in fatty acid increases reaction oxygen species (ROS) production and accumulation of lipid intermediates [e.g. diacylglycerol (DAG)], which have a profound impact on insulin signaling [13]. The c-JUN NH 2-terminal kinase (JNK) and inhibitor $\kappa B$ kinase (IKK), activated by ROS [14, 15], parallel activation of protein kinase $C$ (PKC) by DAG, all of which act to down-regulate insulin action by preventing insulin receptor substrate-1 (IRS1) phosphorylation [13]. High systemic fatty acid uptake also inhibits Akt signaling, resulting in the downregulation of forkhead box $\mathrm{O}$ (FOXO) transcription factors $[16,17]$, while the increased ROS activate nuclear factor kappa B (NF-кB) [18], both of which contribute to the development of cardiac hypertrophy [12, 19].

The muscle ring finger (MuRF) family of ubiquitin ligases, including MuRF2 (Trim55), was identified in 2001 as a highly homologous group of proteins that homo- and hetero-dimerize through their coiled-coil domains [20]. This family of proteins is found in striated muscle, including skeletal and cardiac myocytes and was originally found to be a critical regulator of microtubule assembly during models of skeletal muscle development $[21,22]$. Recent studies have detailed the importance of MuRF2 in the earliest stages of skeletal muscle differentiation and myofibrillogenesis in vivo [23]. In the present study, we identify that endogenous cardiomyocyte MuRF2 inhibits multiple PPAR isoforms, primarily PPAR $\gamma$ (but to a lesser extent PPAR $\delta / \beta$ and PPAR $\alpha$ ). Given the relative importance of PPARs in the development of diabetic cardiomyopathy and the downstream pathophysiology, we challenged MuRF2-/- mice to a $60 \%$ fat diet-induced cardiomyopathy recently described $[24,25]$. With PPAR signaling at the center of regulating fatty acid oxidation and mediating the pathogenesis of type $2 \mathrm{DM}$ induced cardiomyopathy, we hypothesized that if MuRF2-/- hearts had enhanced PPAR signaling, they would undergo an accelerated cardiomyopathy due to MuRF2's direct regulation of PPAR activity. We identified that MuRF2-/- hearts undergo an exaggerated diabetic cardiomyopathy, resulting from MuRF2's multi-ubiquitination of PPAR $\alpha$ and PPAR $\gamma 1$ in a proteasome-independent (non-degradatory) mechanism. These studies identify the first ubiquitin ligase to regulate PPAR via post-translational ubiquitination.

\section{Methods}

\section{Animals and high fat diet-induced diabetic} cardiomyopathy model

All experiments described used age-matched mice or littermates, male and female. All experiments were approved by the Institutional Animal Care and Use Committee (IACUC) review boards at the University of North Carolina and were performed in accordance with federal guidelines. Ten week-old MuRF2-/- and strainmatched wild type mice [26] were fed a high fat diet $(60 \%$ fat, $20 \%$ protein, and $20 \%$ carbohydrates) for 26 weeks as previously described [24]. Baseline body weight, blood glucose, serum insulin, serum triglyceride, and total cholesterol levels along with cardiac function were obtained prior to starting the diet. Body weight, blood glucose, and serum insulin levels measured every 2 weeks; echocardiography was performed every 3 weeks. An MRI was performed at baseline, 6,12 , and 22 weeks to detect body composition changes. After 26 weeks, mice were anesthetized with isoflurane, euthanized with cervical spine dislocation, and heart, liver, gastrocnemius, soleus, and tibialis anterior muscles were collected in cryovials, flash frozen, and stored at $-80^{\circ} \mathrm{C}$. 


\section{Mouse echocardiography}

Conscious transthoracic echocardiography was performed on mice at the indicated time points using a VisualSonics Vevo 2100 ultrasound biomicroscopy system (VisualSonics, Inc., Toronto, Ontario, Canada). Investigators were blinded to mouse genotype. Two-dimensional M-mode echocardiography was performed in the parasternal long-axis view at the level of the papillary muscle on loosely restrained mice. Anterior and posterior wall thickness was measured as distance from epicardial to endocardial leading edges. Left ventricular internal diameters were also measured. Left ventricular systolic function was assessed by ejection fraction (LV EF\% $=[(\mathrm{LV}$ Vol; d-LV Vol; s/LV Vol; d) $\times 100$ ] and fractional shortening $(\% \mathrm{FS}=[(\mathrm{LVEDD}-\mathrm{LVESD}) / \mathrm{LVEDD}] \times 100)$. Measurements represent the average of three cardiac cycles from each mouse.

\section{Body composition measurement}

Conscious low-resolution nuclear magnetic resonance imaging was used to measure body composition of each mouse at baseline, 6, 12, and 22 weeks using an EchoMRI 3-in-1 Body Composition Analyzer for Live Small Animals (Mice) (EchoMRI, LLC, Houston, TX, USA) [27]. Body fat and lean body mass was then calculated as a proportion of total body weight collected just prior to analysis as previously described [28].

\section{Blood collection, serum separation, and methods for glucose, insulin, triglyceride, and total cholesterol measurements}

After overnight fast, $\sim 200 \mu \mathrm{l}$ whole blood was collected by submandibular vein lancet bleed (glucose) or brachial sinus puncture (remaining assays). One microliter whole blood was analyzed via glucometer (PrecisionXtra, Abbott Diabetes Care Inc., Alameda, CA, USA) and test strip (Abbott Diabetes Care Ltd., Witney, Oxon, UK). Blood collected in serum separator tubes for the remaining tests was incubated on ice for $90 \mathrm{~min}$, and centrifuged at $1,600 \times g\left(20 \mathrm{~min}\right.$ at $\left.4^{\circ} \mathrm{C}\right)$. Insulin levels were measured using the Insulin Enzyme Immunoassay Kit (Cayman Chemical, Cat. \#589501, Ann Arbor, MI 48108, USA) according to the manufacturer's instructions as previously described [29]. Serum triglyceride and cholesterol levels were measured using an automated chemical analyzer (Vitro 350, OrthoClinical Diagnostics Company, Rochester, NY, USA).

\section{Fatty acid extraction and triglyceride assay}

Fatty acid extraction and tissue triglyceride concentrations were determined on flash frozen heart tissue, liver tissue, and skeletal tissue as previously described [30]. Briefly, 25-50 mg of heart, liver and skeletal muscle was homogenized 15-30 s with a bladed homogenizer (Power Gen 125, Cat. \#14-261, setting 6, Fisher Scientific, Inc., Pittsburgh, PA, USA) in $10 \times(\mathrm{v} / \mathrm{w})$ ice cold lysis buffer [20 mM Tris base, 1\% Triton-X100, $50 \mathrm{mM}$ $\mathrm{NaCl}, 250 \mathrm{mM} \mathrm{NaF}, 5 \mathrm{mM}$ Na4P2O7-10H2O, 1 tablet protease inhibitor (Roche Inc., Cat. \#11836153)] and incubated at $4^{\circ} \mathrm{C}$ for $1 \mathrm{~h}$. Two hundred microliters of homogenate was transferred to chloroform resistant tubes, mixed with $0.4 \mathrm{ml}$ methanol and $0.8 \mathrm{ml}$ chloroform, placed on the rocker at $4^{\circ} \mathrm{C}$ for at least $30 \mathrm{~min}$. Potassium chloride $(0.24 \mathrm{ml} 0.88 \% \mathrm{KCl})$ was added, samples vortexed, and centrifuged at $1,000 \times g$ for $15 \mathrm{~min}$ at $4^{\circ} \mathrm{C}$. The bottom layer of $\mathrm{CHCl}_{3}$ was then transferred and this process was repeated with another $0.8 \mathrm{ml}$ of chloroform and the combined $\mathrm{CHCl}_{3}$ layers were then dried under $\mathrm{N}_{2}$. One hundred microliters of a tert-butanol:methanol:Triton $\mathrm{X}-100$ solution (3:1:1, $\mathrm{v} / \mathrm{v} / \mathrm{v}$ ) was added to each tube and samples were stored at $-20^{\circ} \mathrm{C}$. Glycerol standard $2.5 \mathrm{mg} / \mathrm{dl}$ (Sigma, Inc., Cat. \#G1394), free glycerol reagent (Sigma Aldrich, Inc., Cat. \#F6428) and triglyceride reagent (Sigma Aldrich, Inc., Cat. \#T2449) were used to measure triglyceride concentrations. Five microliters of the samples were added to a 96-well plate. Working reagent was added to the samples (four volumes of free glycerol reagent: 1 volume of triglyceride reagent). This was left to incubate, rocking, at room temperature for $15 \mathrm{~min}$. Then absorbance was measured per sample at $540 \mathrm{~nm}$ using the Clariostar High Performance Multimode Microplate Reader (BMG LABTECH, San Francisco, CA, USA) and normalized to tissue weight.

\section{Tissue glycogen assay (acid hydrolysis method)}

Tissue glycogen was measured from heart, liver and skeletal muscle using a colorimetric tissue glycogen assay kit (Sigma, Inc., Cat. \#G3293) as previously described [31]. Briefly, 15-25 $\mathrm{mg}$ of tissue was powdered in liquid nitrogen, collected in a pre-chilled $2 \mathrm{ml}$ tube, $0.5 \mathrm{ml}$ $1 \mathrm{~N} \mathrm{HCl}$ added, then homogenized with bladed homogenizer (Fisher Scientific, Power Gen 125, Cat. \#14-261, setting 6, Pittsburgh, PA, USA) under a hood. The resulting homogenate $(100 \mu \mathrm{l})$ was quickly added to $100 \mu \mathrm{l} 1 \mathrm{~N}$ $\mathrm{NaOH}$ and kept on ice until heated in $\mathrm{HCl}$ at $95^{\circ} \mathrm{C}$ for $90 \mathrm{~min}$, mixing every $30 \mathrm{~min}$, cooled to $\mathrm{RT}$ and $0.4 \mathrm{ml}$ $1 \mathrm{~N} \mathrm{Na} \mathrm{OH}$ was added to neutralize the sample. After the sample was centrifuged at $14,000 \times g$ for $10 \mathrm{~min}$ at RT, the supernatant was used for glucose analysis using a hexokinase-dependent assay kit (Sigma, Inc., Cat. \#G3293) according to the manufacturer's instructions. Briefly, $10 \mu \mathrm{l}$ (liver) or $20 \mu \mathrm{l}$ (heart and gastrocnemius) of supernatant was put into a 96-well plate, mixed with $200 \mu \mathrm{l}$ of reagent, incubated at room temperature for $15 \mathrm{~min}$, and the absorbance was measured at $340 \mathrm{~nm}$. 


\section{Cell culture}

Cos-7 and HEK293 cells were cultured in DMEM containing 10\% FBS, $100 \mathrm{unit} / \mathrm{ml}$ penicillin and $0.1 \% \mathrm{mg} /$ $\mathrm{ml}$ streptomycin. HL-1 cardiomyocytes were cultured in supplemented Claycomb medium containing 10\% FBS, $100 \mathrm{unit} / \mathrm{ml}$ penicillin, $0.1 \% \mathrm{mg} / \mathrm{ml}$ streptomycin, $0.1 \mathrm{mM}$ norepinephrine and $2 \mathrm{mM} \mathrm{L}$-glutamine. All cells were incubated at $37^{\circ} \mathrm{C}$ in a $5 \% \mathrm{CO}_{2}$ humidified atmosphere.

\section{Confocal microscopy}

HL-1 cardiomyocytes $\left(2.5 \times 10^{5} /\right.$ well/50\% confluent $)$ plated on Gelatin/Fibronectin were co-transfected with Flag-PPAR $\gamma 1$ and HA-MuRF2 using Lipofectamine LTX \& PLUS (Invitrogen, lot\#1397274) according to the manufacturer's instructions. The ratios of LTX/DNA and PLUS/DNA $(\mu \mathrm{l} / \mu \mathrm{g})$ both were $2: 1$. Equal amounts of DNA were transfected by adjusting with empty vectors. After $48 \mathrm{~h}$ of transfection, the cells were fixed with $4 \%$ paraformaldehyde and blocked in $5 \%$ goat serum with $0.2 \%$ TritonX-100 at room temperature for $1 \mathrm{~h}$. Cells were incubated with $\mathrm{Rb}$ anti-Flag (Sigma F7425, 1:100, $4^{\circ} \mathrm{C}$, overnight or Ms anti-HA (Sigma H9658, 1:100, $4^{\circ} \mathrm{C}$, overnight). Cells were washed and incubated with antiMs 488 to detect HA-MuRF2 (Invitrogen, 1:1,000) or anti Rb 568 (Invitrogen, 1:1,000) for $1 \mathrm{~h}$ at room temperature. The membranes were cut into $1 \times 1 \mathrm{~cm}$ sections and mounted to glass slides with Fluoro-Gel Anti-fade mounting medium with DAPI (EMS, Hatfield, PA Cat. \#17983-20) and analyzed by fluorescent confocal microscopy using a Zeiss CLSM 710 Spectral Confocal Laser Scanning Microscope.

\section{RNA isolation and quantitative PCR analysis of PPAR-regulated gene expression}

Total RNA was isolated using TRIzol reagent according to the manufacturer's protocols (Life Technologies, Inc., Cat. \#15596-026). Approximately $25 \mathrm{mg}$ of cardiac ventricular tissue was put into TRIzol reagent and homogenized on ice (Fisher Scientific, Power Gen 125, setting 5). Total mRNA expression was determined using a twostep reaction. cDNA was made from total RNA using the iScript $^{\mathrm{TM}}$ Reverse Transcription Supermix for RT-qPCR kit (Cat. \#170-8841, BIO-RAD), with a total volume of $20 \mu \mathrm{l}$ per reaction. The complete reaction mix was incubated in an Eppendorf Cycler (Hamburg, Germany) using the following protocol: priming $5 \mathrm{~min}$ at $25^{\circ} \mathrm{C}$, reverse transcription $30 \mathrm{~min}$ at $42^{\circ} \mathrm{C}$, RT inactivation $5 \mathrm{~min}$ at $85^{\circ} \mathrm{C}$. PCR products were amplified on a Roche Lightcycler 480II system using cDNA, Taqman Probes (Applied Biosciences $^{\mathrm{TM}}$ ), and Lightcycler 480 Probe Master Mix 2X (Cat. \#04 707494 001). The TaqMan probes used in this study are Mm00430615_m1 (ACC1), Mm00443579_m1 (ACOX1), Mm00475794_m1 (ADRP),
Mm00599660_m1 (LCAD), Mm00431611_m1 (MCAD), Mm00440939_m1 (PPAR $\alpha), M m 01305434 \_m 1$ (PPAR $\left.\beta\right)$, Mm00443325_m1 (PDK4), Mm00487200_m1 (CPT1b), Mm00441480_m1 (Glut1, Slc2a1), Mm01245502_m1 (Glut4, Slc2a4), Mm01309576_m1 (PFK), Mm00432403_ m1 (CD36, FAT), Mm01185221_m1 (MuRF1, Trim63), and Mm01292963_g1 (MuRF2, Trim55), Hs99999901_ s1 (18S), Mm00440359_m1 ( $\alpha-$ MHC, Myh6), Mm00600555_m1 ( $\beta-$ MHC, Myh7), Mm01255747_g1 (ANP), Mm00435304_g1 (BNP), Mm00808218_g1 (SK $\alpha$-actin) (Applied Biosystems, Inc., Foster City, CA, USA). Assay of PPAR $\gamma 1$ was performed using the Roche Universal Probe technology, including forward primer (gggctgaggagaagtcacac) and reverse primer (gggctgaggagaagtcacac) in conjunction with UPL probe \#92 (Roche, Inc., Cat. \#04692098001). Samples were run in triplicate and relative mRNA expression was determined using $18 \mathrm{~S}$ as an internal endogenous control. RNase-free water, $2 \times$ Master Mix, Taqman Probe or Roche UPL primer and probe, and cDNA were used for each reaction.

\section{Western blot}

Western analysis of ventricular tissue was performed on lysates created from $\sim 25 \mathrm{mg}$ tissue placed in $1 \times$ Cell Signaling Lysis Buffer (for $10 \mathrm{ml}: 1 \mathrm{ml} \mathrm{10 \times Cell} \mathrm{Signaling}$ Lysis Buffer, Cat. \#9803S; 0.108 g $\beta$-glycerol phosphate, Sigma, Cat. \#G6251; 1 tablet protease inhibitor, Roche Cat. \#11 836153 001; $100 \mu$ l 100X phosphatase inhibitor cocktail, Roche Cat. \#04 906837 001) and was homogenized on ice (Fisher Scientific, Power Gen 125, setting 5) for $15-20 \mathrm{~s}$. The homogenate was incubated on ice for $30 \mathrm{~min}$, centrifuged at $4^{\circ} \mathrm{C}, \times 16,000 \times g$ for $15 \mathrm{~min}$ and the supernatant stored at $-80^{\circ} \mathrm{C}$. Protein concentration was determined using the Bio-Rad DC Protein Assay Reagent Package (Bio-Rad Laboratories, Inc., Hercules, CA, Cat. \#500-0116). Proteins (30-50 $\mu \mathrm{g} / \mathrm{lane})$ were resolved on NuPAGE Bis-Tris or Tris-Acetate 10 well gels. Mouse

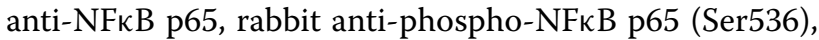
rabbit anti-phospho-NFкB p65 (Ser468) were used to measure NFKB signaling (Cell Signaling Technologies, Cat. \#6956, \#3033, and \#3039, 1:500). IRS-1 signaling was detected using rabbit anti-phospho-IRS-1 (Ser1101) and rabbit anti-IRS-1 (Cell Signaling Technologies, Inc. Cat. \#2385 and \#2383, 1:500). cJun signaling was detected by rabbit anti-p-cJun (Ser73), Rb anti-p-cJun (Thr91) or Rb anti-cJun 60A8 (Cell Signaling Technologies, Cat. \#9164, \#2303, \#9165, 1:500). Rabbit anti-PPAR $\alpha$ (Abcam Inc. Cat. \#24509,1:1000), rabbit anti-PPAR $\beta / \delta$ (Abcam Inc. Cat. \#8937, 1:500), and rabbit anti-PPAR $\gamma$ (Cell Signaling Technologies, Inc. Cat. \#2443, 1:500) were used to measure protein expression of the PPAR isoforms. MuRF2 protein expression was detected by goat anti-MuRF2 (Abcam Inc. Cat. \#4387, 1:1000). Primary antibodies were 
diluted in $5 \%$ milk or bovine serum albumin and incubated at $4^{\circ} \mathrm{C}$ overnight. HRP-labeled secondary antibodies against mouse (Sigma \#A9917, 1:10,000), goat (Sigma \#A4174, 1:10,000), and rabbit (Sigma \#A9169, 1:5,000) were used to detect the primary antibodies diluted in $1 \times$ TBS-T and incubated $1 \mathrm{~h}$ at room temperature. Mouse anti- $\beta$-actin (Sigma, Inc., Cat. \#A2228, 1:4,000) and mouse anti-GAPDH (Sigma, Inc., Cat. \#G8795, 1:4,000) were used as a loading controls throughout. Secondary antibody HRP was detected using ECL Select (GE Healthcare, Cat. \#RPN2235) and imaged using the MultiDoc-it Imaging System (UVP, LLC Ultra-violet Products, Ltd., Upland, CA, USA).

\section{Immunoprecipitation studies}

HEK293 cells were cotransfected with p3XFlagPPAR $\gamma 1$ and pcDNA3.1-HA-MuRF2 or pcDNA3.1-HAMuRF2 $\triangle$ Ring DNA plasmids. After $28 \mathrm{~h}$ of transfection, cells were lysed using RIPA buffer (Sigma, Inc., Cat. \#R0278). Protein concentration was determined using Bio-Rad DC Protein Assay. $60 \mu \mathrm{l}$ EZview Red Anti-Flag M2 Affinity Gel beads (Sigma, Inc., Cat. \#F2426) were washed twice using $1 \times$ TBS, after the addition of $250 \mu \mathrm{g}$ protein lysates, samples were gently agitated on a roller shaker overnight at $4^{\circ} \mathrm{C}$. After three washes with $1 \mathrm{xTBS}$, the proteins were eluted by $30 \mu \mathrm{l}$ of $2 \times$ LDS Sample Buffer (NuPAGE LDS Sample Buffer, Lot\#1452697) and boiled for $5 \mathrm{~min}$ at $100^{\circ} \mathrm{C}$. Samples were analyzed by immunoblotting.

\section{Total O-GIcNAc expression}

Total O-GlcNAc expression was determined by SDSPAGE as previously described [32], using anti-O-GlcNAc (RL-2, Santa Cruz Biotechnology, Santa Cruz CA) on PVDF blocked with $1 \%$ bovine serum albumin dissolved in TBS-T solution for $20 \mathrm{~min}$, followed by an overnight incubation with $O$-GlcNAc antibody $(1: 1,000)$ at $4{ }^{\circ} \mathrm{C}$. Secondary antibody (goat-anti-mouse IgG-HRP, Santa Cruz Biotechnologies, Santa Cruz CA; 1:4,000) incubated for $1 \mathrm{~h}$ at room temperature, washed with TBS-T, then visualized with enhanced chemiluminescence $(E C L)$ on the ChemiDoc ${ }^{\mathrm{TM}} \mathrm{XRS}+$ system with Image Lab ${ }^{\mathrm{TM}}$ Software v2.0 (Bio-Rad Laboratories, Hercules CA, USA). Total $O$-GlcNAcylation (per lane) was quantified by the adjusted percentage volume-intensity units of pixels of band $\times \mathrm{mm}^{2}$-after background subtraction using Quantity One Software v4.6.9 (Bio-Rad Laboratories, Hercules CA, USA), and normalized to $\beta$-actin (Abcam, Cambridge MA, USA).

\section{In vitro ubiquitination assay}

Human recombinant GST-E1 (50 nM, Boston, Biochem, Cambridge, MA, Cat. \#E-306), human recombinant
UbcH5c/UBE2D3 (2.5 $\mu \mathrm{M}$, Boston Biochem, Inc., Cambridge, MA, USA, Cat. \#E2-627), human recombinant ubiquitin $(250 \mu \mathrm{M}$, Boston Biochem, Inc., Cat. \#U-100H), human MuRF2 recombinant protein (1 mg, LifeSensors, Cat. \#UB305, Malvern, PA, USA), human PPAR $-\alpha,-\beta$, and $-\gamma$ recombinant protein (500 ng, SigmaAldrich, Inc., St. Louis, MO, USA, Cat. \#SRP2043, Cat. \#SRP2044, and Cat. \#SRP2045, respectively) were added to reaction buffer (50 mM HEPES, pH 7.5) containing $5 \mathrm{mM}$ MgATP solution (Boston Biochem, Inc., Cat. $\# \mathrm{~B}-20$ ) and $0.6 \mathrm{mM}$ DTT then incubated at $37^{\circ} \mathrm{C}$ for $1 \mathrm{~h}$. The reaction was stopped by adding SDS-PAGE sample buffer and heating, then resolved on a $4-12 \%$ Bis-Tris gel with MOPS running buffer (Invitrogen Corp.) and transferred to PVDF membranes for immunoblotting with goat polyclonal anti-MuRF2 antibody (Abcam, Cat. \#Ab4387), rabbit polyclonal anti-PPAR $\alpha$ antibody (Abcam, Cat. \#Ab24509), rabbit polyclonal anti-PPAR $\beta$ antibody (Millipore, Cat. \#AB10094), or rabbit polyclonal anti-PPAR $\gamma$ antibody (Cell Signaling Technology, Cat. \#2443).

\section{Non-targeted metabolomics determination by GC-MS Instrumentation}

Cardiac tissue was flash frozen with liquid nitrogen cooled in a biopress, a fraction weighed $(\sim 25-30 \mathrm{mg}$ weight), finely ground, and added to fresh $50 \%$ acetylnitrile, $50 \%$ water, and $0.3 \%$ formic acid at a standard concentration of $25 \mathrm{mg} / 475 \mathrm{mcl}$ buffer, then fully homogenized on ice for 10-25 s and placed on dry ice/ stored at $-80^{\circ} \mathrm{C}$. Samples were "crash" deprotonized by methanol precipitation and spiked with D27-deuterated myristic acid (D27-C14:0) as an internal standard for retention-time locking and dried. The trimethylsilyl (TMS)-D27-C14:0 standard retention time (RT) was set at ${ }^{*} 16.727 \mathrm{~min}$. Reactive carbonyls were stabilized at $50^{\circ} \mathrm{C}$ with methoxyamine hydrochloride in dry pyridine. Metabolites were made volatile with TMS groups using N-methyl-N-(trimethylsilyl) trifluoroacetamide or MSTFA with catalytic trimethylchlorosilane at $50^{\circ} \mathrm{C}$. GC/MS methods generally follow those of Roessner et al. [33], Fiehn et al. [34], and Kind et al. [35], which used a 6,890 N GC connected to a 5,975 Inert single quadrupole MS (Agilent Technologies, Santa Clara, CA, USA). The two wall-coated, open-tubular (WCOT) GC columns connected in series are both from J\&W/ Agilent (part 122-5512), DB5-MS, $15 \mathrm{~m}$ in length, $0.25 \mathrm{~mm}$ in diameter, with an $0.25-\mathrm{lm}$ luminal film. Positive ions generated with conventional electronionization (EI) at $70 \mathrm{eV}$ are scanned broadly from 600 to $50 \mathrm{~m} / \mathrm{z}$ in the detector throughout the $45 \mathrm{~min}$ cycle time. Data were acquired and analyzed as previously described [36, 37]. 


\section{Statistical analysis}

Sigma Plot 11.0 and Prism 6.0f were used to plot and statistically analyze data. Depending upon the experimental design, several statistical tests were applied to the studies. Student's t test or One Way ANOVA followed by HolmSidak pairwise post hoc analysis was performed, indicated in the figure legends. Significance was determined as $\mathrm{p}<0.05$. Values are expressed as mean $\pm \mathrm{SE}$. Statistical analysis on metabolomics data was performed as previously described [36, 37]. Metaboanalyst (v2.0) run on the statistical package R (v2.14.0) used metabolite peaks areas (as representative of concentration) [38, 39]. These data were first analyzed by an unsupervised principal component analysis (PCA), which identified the presence of the MuRF2-/ - after 26 weeks high fat diet as the principal source of variance. To sharpen the separation between our three groups, data were next analyzed using a partial least squares discriminant analysis (PLS-DA) to further determine which metabolites were responsible for separating these two groups. The specific metabolites contributing most significantly to the differences identified by PLS-DA between MuRF2-/ - and wildtype control group hearts were determined using the variable importance in projection (VIP) analysis in the Metaboanalyst 2.0 environment. The metabolites that best differentiated the groups were then individually tested using the Student's t-test (Microsoft Excel 2011, Seattle, WA, USA). The VIP and t test significant metabolites were matched to metabolomics pathways using the Pathway Analysis feature in Metaboanalyst 2.0. Heat maps of the metabolite data (individual and grouped) were generated using the GENE E software (http://www.broadinstitute. org/cancer/software/GENE-E/index.html).

\section{Results}

We have recently identified that MuRF2, a muscle-specific ubiquitin ligase, is a critical factor that regulates cardiomyocyte size during development in concert with MuRF1 [40]. MuRF2 has also been described as the effector protein in the Titin-nbr1-p62 complex that responds to mechanical changes in the sarcomere to inhibit transactivation of the nuclear transcription factor serum response factor (SRF) [41]. MuRF2's regulation of the nuclear specific SRF was the first indication that MuRF2, found primarily in the cytoplasm, could regulate the activity of nuclear receptors, presumably through direct interaction, ubiquitination, and apparent nuclear export [41]. These findings led us to hypothesize that MuRF2 similarly regulates other nuclear receptors critical to cardiomyocytes. To test this, we used MuRF2-/- mice previously characterized without a cardiac or skeletal muscle phenotype [26]. However, we recently identified that MuRF2-/- hearts exhibited changes in metabolomics signatures, indicating that changes in metabolism are present despite any functional effect at baseline [37]. We initially assayed isolated nuclei from MuRF2-/hearts for their DNA-binding activity contributed by PPAR $\alpha, \operatorname{PPAR} \beta$, and PPAR $\gamma$ as the PPARs have been best described in altering cardiac metabolism [42] and have been reported to be regulated by ubiquitination [43]. To our surprise, we found that MuRF2-/- hearts had significantly increased PPAR activities, with increases in PPAR $\alpha$ (+twofold), PPAR $\beta$ ( $\sim 1.6$ fold), and PPAR $\gamma$ (over + fourfold) activities compared with sibling MuRF2+/+ control mice (Fig. 1a). These findings suggested that endogenous MuRF2 attenuated the activity of all three PPAR transcription factors found in cardiomyocytes. Since MuRF2 is an ubiquitin ligase and PPAR transcription factors have been described with post-translational modification by ubiquitin, we hypothesized that MuRF2 may regulate these PPAR transcription factors in a ubiquitination-dependent manner.

The pathogenesis of diabetic cardiomyopathy involves the enhanced activation of PPAR transcription factors [44]. Diabetic cardiomyopathy is characterized by increased free fatty acid oxidation in parallel with cardiomyocyte insulin resistance [6]. Both the resulting increased fatty acid oxidation and insulin contribute to the decreased ability for the heart to switch away from fatty acid utilization to glucose [45]. Since cardiac MuRF2-/- mice exhibited enhanced PPAR activity, we hypothesized that the induction of diabetic cardiomyopathy would result in both enhanced PPAR activity, resulting in significant cardiac dysfunction compared with wildtype mice. To test this hypothesis, we challenged the MuRF2-/ - mice to a $60 \%$ high-fat diet, which reproducibly induces insulin resistance and diabetic cardiomyopathy (Fig. 1b) [24].

After 26 weeks of high fat diet challenge, MuRF2-/mice had significantly lower blood glucose compared with sibling wildtype controls but no differences in serum insulin levels (Additional file 1: Figure S1a). Serum triglycerides were similarly elevated in MuRF2-/- and wildtype controls after 26 weeks of high fat diet (Additional file 1: Figure S1b). Increased cardiac MuRF2 protein levels were identified after high fat diet (Fig. 1c), paralleling MuRF2 increases identified in human inflammatory dilated cardiomyopathy (http://www.ncbi.nlm.nih.gov/geoprofiles/26614376) and coronary artery atherosclerosis (http:// www.ncbi.nlm.nih.gov/geoprofiles/16462729). MuRF2-/hearts increased total weight more than wildtype controls in high fat diet challenge (Fig. 1d) in addition to having significant increases in overall body weight at any 15,22 , and 25 weeks of HFD (Fig. 1e). However, no significant changes were identified in gastrocnemius, soleus, or tibialis anterior muscles weights (Additional file 1: Figure S1c). 




Echocardiographic analysis of MuRF2-/- hearts at baseline found no deficits in function or differences in measurements (Fig. 2a; Table 1) as previously described
[40, 46]. Significant deficits in heart function were identified in the MuRF2-/- hearts in as little as 6 weeks after the initiation of high fat diet (Fig. 2a, upper left 










panel). MuRF2-/ - hearts were significantly thinner than MuRF2+/+ hearts from 15-26 weeks of high fat diet feeding (Fig. 2a, upper middle panels, Fig. 2b, d). Both MuRF2-/ - and wildtype mice experienced an equal progressive dilation over time on a high fat diet, evidenced by increases in LVESD (Fig. 2a, far right panel). MuRF2-/ - hearts exhibited significant dysfunction as early as 6 weeks of HFD compared to MuRF2+/+ hearts (Fig. 2b). MuRF2-/- hearts were significantly larger than MuRF2+/+ hearts after 26 weeks high fat diet (Fig. 2b-d). Diabetic cardiomyocyte-related changes in myosin heavy chain gene expression were next investigated to determine differences between groups. Comparable increases in $\beta M H C$ were seen in MuRF2-/ - and wildtype hearts (Fig. 2e), consistent with previous studies identifying these increases [47]. MuRF2-/- cardiac expression of skeletal muscle $\alpha$-actin and $\alpha \mathrm{MHC}$ were increased in chow control hearts compared to wild type mice, and MuRF2-/- skeletal muscle $\alpha$-actin was significantly increased as compared to wild type mice after 26 weeks high fat diet (Fig. 2e). No difference existed in $\alpha \mathrm{MHC}$ after 26 weeks of high fat diet in either MuRF2-/- or MuRF2 +/+ mice (Fig. 2e), although this is reported in other models of diabetic cardiomyopathy $[48,49]$. Brain natriuretic protein (BNP) mRNA was decreased in both MuRF2-/- and controls after 26 weeks high fat diet feeding (Fig. 2e). Taken together, these studies identified that MuRF2-/- hearts failed sooner than MuRF2+/+ hearts, resulting in larger hearts, including LV wall thickness and heart weights after 26 weeks high fat diet challenge.

LV remodeling is a distinctive finding in the pathogenesis of diabetic cardiomyopathy. These changes include the development of fibrosis, resulting from the accumulation of extracellular collagen [50,51]. Reduced MMP2 activity [52] and O-GlcNAcylation stimulated cardiac fibroblast collagen synthesis has been reported [53]. In this particular model, less than $2 \%$ fibrosis was identified throughout the heart in MuRF2-/- and wildtype controls (Fig. 3a). However, MuRF2-/- hearts revealed a parallel reduction in vimentin-positive fibroblasts (Fig. 3b). Throughout the course of the study, only one mouse died a Collagen-Positive (Masson's Trichrome) Cardiac Cross-Section Analysis

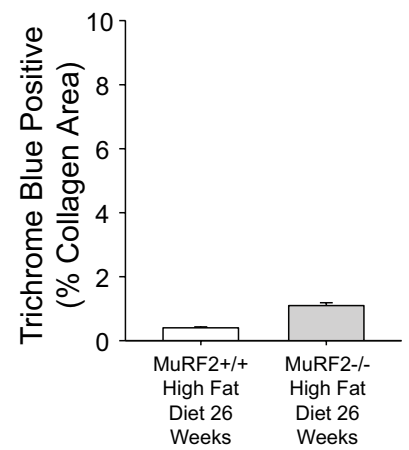

b Vimentin-Positive Cells (Fibroblasts) Cardiac Cross-Section Analysis

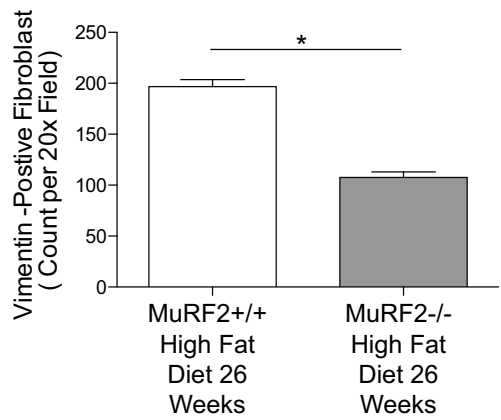

MuRF2+/+ High Fat Diet 26 Weeks
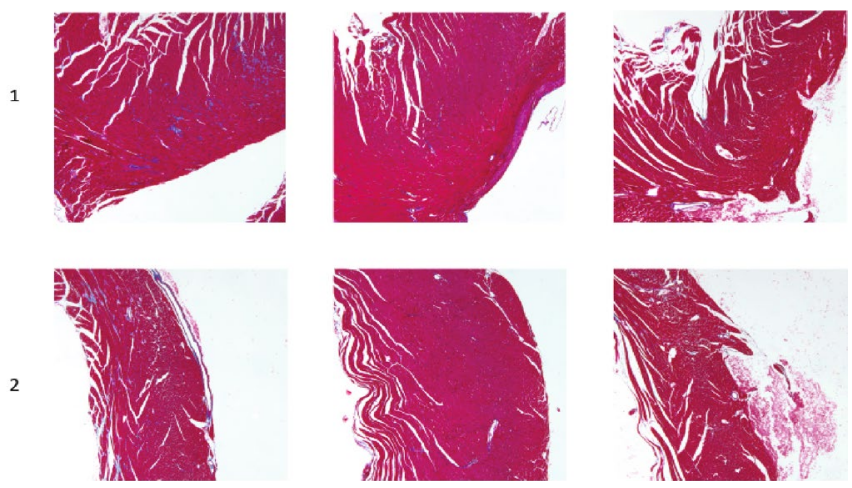

MuRF2+/+ High Fat Diet 26 Weeks

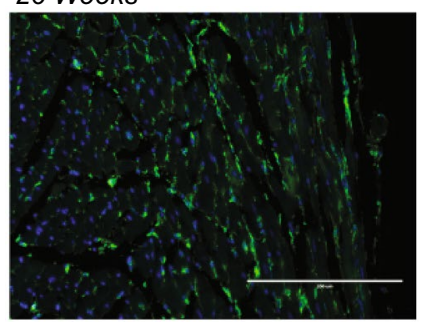

M2C7M01
MuRF2-/- High Fat Diet 26 Weeks

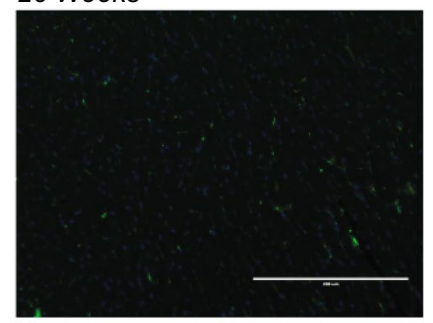

M2C8M00

Fig. 3 Histological analysis of cardiac fibrosis. a Fibrosis analysis of Masson's Trichrome-stained heart sections of MuRF2-/- and wild type hearts after 26 weeks high fat diet reveals no significant differences. b Confocal immunofluorescence analysis of vimentin (fibroblasts) in cardiac crosssections from MuRF2-/- mice after 26 weeks HFD ( $N=3$ /group). Values expressed as Mean \pm SE. Statistical analysis was performed using a Student's t test. ${ }^{*} p<0.001,{ }^{* *} p<0.01,{ }^{\#} p<0.05$. 
at 21 weeks of high fat diet. This wildtype mouse, interestingly, revealed almost $4 \%$ fibrosis (Additional file 2: Figure S2c) with amorphous waxy infiltrates and leukocyte infiltrates (Additional file 2: Figure S2b) not seen in either MuRF2-/- or wildtype hearts after 26 weeks high fat diet (Additional file 2: Figure S2a). Overall, while MuRF2-/ - hearts have significant increases in fibrosis, the total fibrosis is minimal and does not account for the large changes in cardiac size, dysfunction, and suggests other non-structural signaling pathways likely are involved in the MuRF2-/- exaggerated cardiac dysfunction in diabetic cardiomyopathy.

Cardiac PPAR $\alpha$, PPAR $\beta$, and PPAR $\gamma 1$ have pivotal roles in the pathophysiology of diabetic cardiomyopathy [44].
Therefore, we next investigated the expression of cardiac PPAR isoform regulated genes previously described in vivo [54-56]. Gene expression of the cardiac PPAR $\alpha$ target genes (not regulated by cardiac PPAR $\beta$ i.e. glut 1 and $c d 36$ ) (Fig. 4a), cardiac PPAR $\beta$ target genes associated with glucose metabolism (not regulated by cardiac PPAR $\alpha$, i.e. glut4, pfk, acc1, mcad, and lcad) (Fig. 4b, c), and cardiac PPAR $\gamma 1$-regulated cardiac genes (i.e. acox1, adrp, cpt1b, and pdk4) (Fig. 4d) were evaluated in MuRF2-/- mouse hearts. Notably, MuRF2-/- hearts challenged with high fat diet exhibited significantly increased levels of PPAR $\alpha$-regulated genes (Fig. 4a), PPAR $\beta$-regulated genes associated with fatty acid metabolism (Fig. 4c), and PPAR $\gamma 1$-regulated genes (Fig. 4d). a Cardiac PPAR $\alpha$ target gene expression

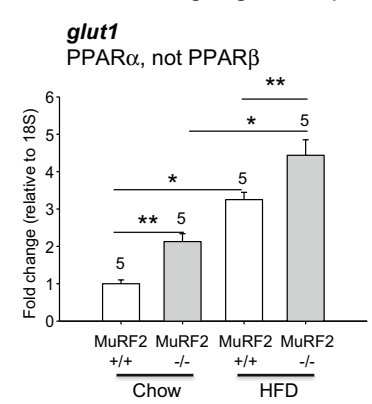

\section{cd36}

PPAR $\alpha$, not PPAR $\beta$

PPAR $\gamma 1$

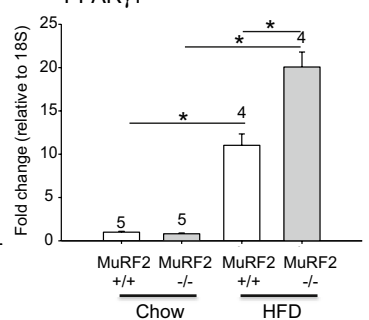

C Cardiac PPAR $\beta$ target gene expression-Fatty Acid Metabolism


d Cardiac PPAR 1 target gene expression
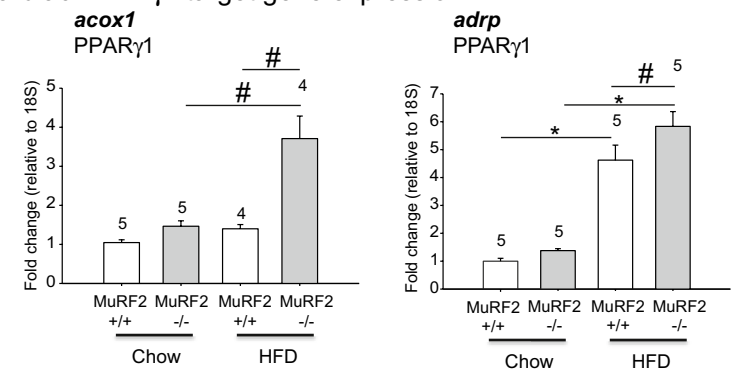

b Cardiac PPAR $\beta$ target gene expression-Glucose Metabolism glut4 PPAR $\beta$, not PPAR $\alpha$

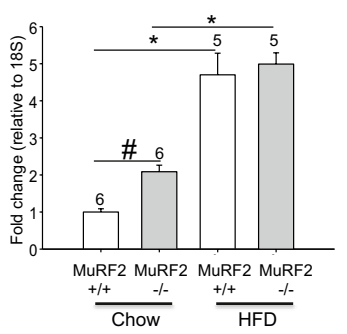

PPAR $\beta$, not PPAR $\alpha$
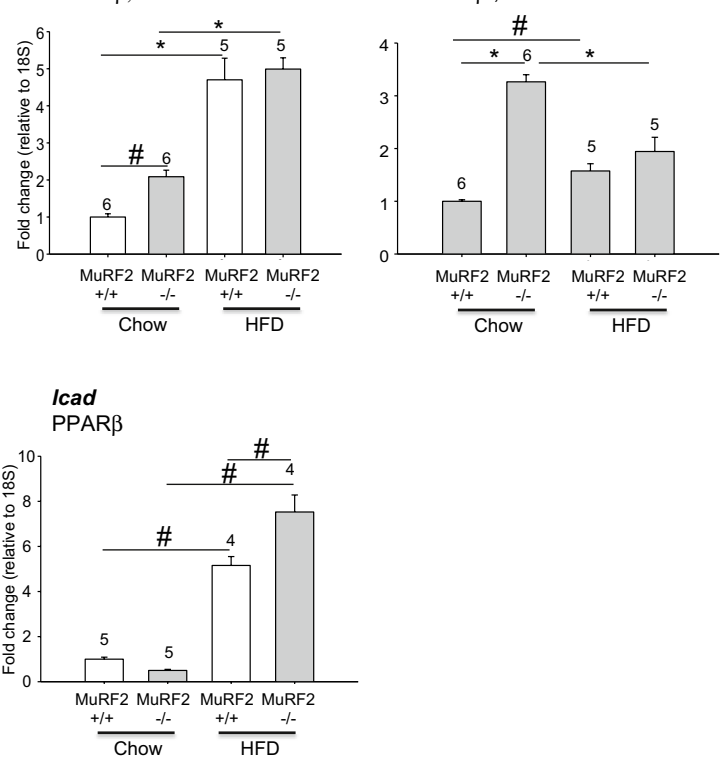

Fig. 4 High fat diet-induced increases in PPAR-regulated gene (mRNA) levels are exaggerated in cardiac MuRF2-/- hearts. RT-qPCR analysis of cardiac mRNA of genes identified as PPAR isoform "specific" based on cardiac transgenic PPAR $\alpha$, PPAR $\beta$, and PPAR $\gamma 1$ studies as described in the text. a Cardiac PPAR $\alpha$ target gene expression, b PPAR $\beta$-regulated mRNA target genes involved in glucose metabolism, c PPAR $\beta$-regulated mRNA target genes involved in fatty acid metabolism. d PPAR 1-regulated mRNA target genes. Values expressed as Mean \pm SE. Values expressed as Mean \pm SE. The significance of observed differences in grouped mean values was determined using a One Way ANOVA followed by Holm-Sidak pairwise post hoc analysis. N per group indicated above graph. ${ }^{*} p \leq 0.001,{ }^{* *} p<0.01,{ }^{*} p<0.05$. 
MuRF2-/ - hearts did not differ from MuRF2+/+ hearts in PPAR $\beta$-regulated target genes associated with glucose metabolism (glut4 and $p f k$, Fig. 4c). Like the PPAR isoform activities assays of the MuRF2-/- heart nuclei demonstrated, MuRF2-/- hearts exhibited enhanced PPAR activities. At the mRNA level, MuRF2-/- hearts exhibited significant increases in PPAR $\alpha$ compared with wildtype mice, but no differences in PPAR $\beta$ or PPAR $\gamma 1$ (Additional file 3: Figure S3).

Fatty acids are the primary fuel of the heart in addition to being ligands for the PPAR transcription factors. High fat diets have been reported to increase cardiac triglyceride content [57]. The increased storage fat (as myocardial triglyceride) that occurs in the development of type 2 diabetic cardiomyopathy has been hypothesized as one mechanism that free fatty acids are toxic to the heart [58-60]. The mishandling of cardiac glycogen is also a frequent manifestation of diabetic cardiomyopathy [61]. We hypothesized that increased levels of fatty acid in the MuRF2-/- hearts could contribute to the enhanced heart failure they demonstrated in diabetic cardiomyopathy. Since MuRF2 has been reported in the heart and skeletal muscle, in addition to the liver, we measured cardiac triglycerides and glycogen after 26 weeks of high fat diet to determine if alterations in these storage forms of fat and glucose could be contributing to the increased heart weight or dysfunction in the MuRF2-/- hearts (Fig. 5). Compared to the control feeding, both MuRF2-/- and MuRF2+/+ hearts had increased cardiac triglyceride levels (Fig. 5a). However, MuRF2-/- hearts did not have significantly different triglyceride levels compared with wildtype after 26 weeks high fat diet feeding. MuRF2-/- liver and skeletal muscle after 26 weeks high fat diet feeding was similarly not significantly different from wildtype controls (Fig. 5a). MuRF2-/ - hearts from dietary controls (chow) had significantly decreased cardiac glycogen compared with wildtype hearts (Fig. 5b). While MuRF2-/- hearts accumulated significantly increased glycogen after 26 weeks high fat diet, the increases MuRF2-/- liver and skeletal muscle accumulated did not reach significance (Fig. 5b). Together, these studies illustrate that the MuRF2-/hearts are able to store fat (as triglyceride), but have alterations in glycogen storage capacity both at steady state (baseline) conditions and after high fat diet challenges. Akt and glycogen synthase kinase (GSK)-3 $\beta$ are reported to be decreased in diabetic cardiomyopathy, along with increases in fibrosis and inflammation $[48,62]$.

Recent studies have demonstrated a role for PPAR activation in developing adiposity and weight gain in models of diabetes. In one study, treatment with rosiglitazone in mouse models of diabetes was shown to promote increases in cardiac size and enhanced fat volume [63]. Similarly, rosiglitazone side effects in patients have revealed increasing fat gain [64]. At baseline, MuRF2-/- mice had comparable fat and lean body mass as wildtype controls (Fig. 5c). However, during the development of insulin resistance, MuRF2-/mice demonstrated significantly more fat mass at 6 and 12 weeks of high fat diet, but no changes in lean body mass (Fig. 5c). While the specific mechanisms by which rosiglitazone regulates fat mass is not completely clear, the enhanced PPAR activities seen in MuRF2-/- mice may be one contributing factor to the accumulation of fat mass during which cardiac function is significantly worse than wildtype mice challenged in parallel with a high fat diet.

The post-translational modification of intracellular proteins by $\mathrm{O}$-linked $\mathrm{N}$-acetylglucosamine (O-GlcNAc) in diabetes is a result of the excess glucose that drives the reaction. O-GlcNAc, in concert with ubiquitin, mediates several aspects of diabetic cardiomyopathy [53, 65-68]. O-GlcNAc modified proteins impair cardiomyocyte calcium cycling via its direct effects on phospholamban [68, 69]. O-GlcNAcylation also blunts autophagy, down regulates Nkx2.5 expression, and stimulates cardiac fibroblast collagen synthesis to mediate cardiac dysfunction [53, $65,66]$. Therefore, we measured the amount of O-GlcNAc proteins in MuRF2-/- heart, hypothesizing that the loss of MuRF2 cleared fewer O-GlcNAc-modified proteins, to mediate the enhanced cardiomyopathy seen in vivo. Immunoblot analysis of O-GlcNAc-modified proteins in MuRF2-/- hearts demonstrated no differences from wildtype hearts when mice were fed a chow diet or 26 weeks of high fat diet (Additional file 4: Figure S4). While modest increases in O-GlcNAc levels were identified after 26 weeks of high fat diet, as expected with the observed hyperglycemia, differences in O-GlcNAc could did not appear to contribute to the exaggerated MuRF2-/- cardiac dysfunction.

Since NF- $\mathrm{kB}$ signaling, defective insulin signaling, JNK signaling, and alterations in autophagy have been implicated in the pathogenesis of diabetic cardiomyopathy [19, 70-72], we next determined if MuRF2-/- hearts had alterations in these processes that may explain their more severe phenotype. After 26 weeks of high fat diet, MuRF2-/ - hearts did not exhibit enhanced NF- $\kappa B$ activity (determined by p-p65 western blot), decreased IRS-1 signaling (determined by p-IRS-1 western blot), or alternations in JNK signaling (determined by p-cJun) (Additional file 5: Figure S5a). Similarly, measures of cardiac autophagy in MuRF2-/- hearts after high fat diet did not differ from wildtype controls, including autophagy flux (LC3II/LC3I proteins ratio post-bafilomycin treatment by western blot), p62, or VPS34 protein levels by western blot (Additional file 5: Figure S5b). These studies 


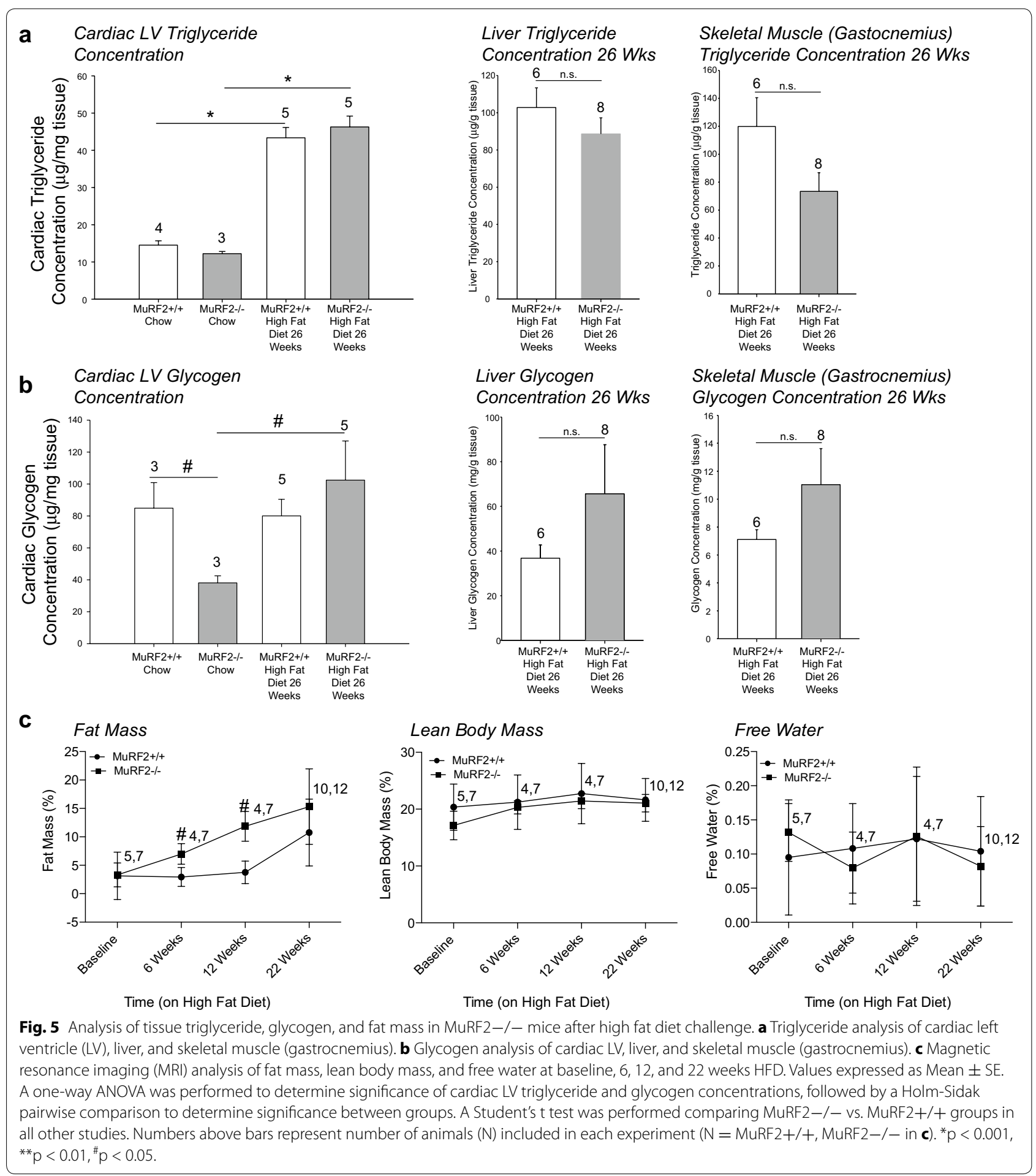

demonstrated that the more severe MuRF2-/- phenotype was not due to alterations in NF- $\kappa \mathrm{B}$, insulin, or JNK signaling or reductions in autophagy that have been reported to result in more severe diabetic cardiomyopathy [19].
Evidence from a variety of cell culture studies have implicated ubiquitin as a post-translational modifier of PPAR transcription factors and their coreceptors/coactivators [43]. These have been in liver, lung, fibroblast, adipocytes, and macrophage (as recently reviewed [43]). 
These studies have found that the ubiquitin-mediated inhibition of PPAR isoforms PPAR $\alpha$ PPAR $\beta$, and PPAR $\gamma$ are: 1) ligand-dependent (ligand is required for ubiquitination and/or degradation to occur); and 2) the ratio of ubiquitin ligase (e.g. MDM2 [73]) determines activation (e.g. MDM2:PPAR $\alpha$ ratio < 1) or inhibition (e.g. MDM2:PPAR $\alpha>1$ [73]). Since considerable evidence shows that MuRF2-/- hearts enhance PPAR-activity suggesting that endogenous cardiac MuRF2 inhibits PPAR activities by nuclear PPRE-binding (Fig. 1a) and PPARregulated gene expression (Fig. 4), we next focused on how the muscle-specific ubiquitin ligase MuRF2 might exert its inhibitory effects based on our current knowledge of how ubiquitin regulates PPAR in cancer cells.

Like other ubiquitin ligases, MuRF2 interacts with a number of protein substrates. Notably, MuRF2 and MuRF1 redundantly interact with roponin-I (TnI), TnT, myosin light chain 2 , and T-cap (telethonin) in yeast twohybrid studies [74]. Unlike MuRF1, MuRF2 has not been shown to degrade any of these substrates (as recently reviewed [75] ). But critical regulation of microtubule, intermediate filament, and sarcomeric M-line stability during striated muscle development [22] and regulation of E2F activity [40]. Understanding that high fat diet induced MuRF2 expression, we next identified PPAR $\alpha$, PPAR $\beta$, and PPAR $\gamma 1$ (as the PPAR $\gamma 2$ isoform is restricted to adipocytes) (Fig. 6a). Interestingly, in steady state conditions, cardiac PPAR $\alpha$ and PPAR $\alpha$ protein levels in MuRF2-/- mice did not differ compared with wildtype controls. However, PPAR $\gamma 1$ levels were slightly (and significantly) increased at baseline (Fig. 6a, far right). After challenge with PPAR ligands (free fatty acids from high fat diet) for 26 weeks, no differences in MuRF2-/- cardiac PPAR $\alpha$ and PPAR $\gamma 1$ were identified by immunoblot analysis, but a significant increase in PPAR $\beta$ protein expression was identified (Fig. 6a). Taken together, these studies illustrate that the steady state levels of cardiac PPAR $\alpha$ and PPAR $\gamma 1$ isoforms are not affected by the presence of MuRF2 or its increase (Fig. 1c) after high fat diet challenge. Moreover, these results suggest that MuRF2's changes in PPAR $\alpha$ and PPAR $\gamma 1$ activities could be due to one of the multiple non-canonical post-translational modifications by ubiquitin (e.g. mono-ubiquitination) that are not associated with proteasome dependent and degradation. How MuRF2 is regulating PPAR $\beta$ without being able to ubiquitinate it directly (Fig. 6f) is unclear. But the mechanism would be indirect include the possibility that MuRF2 it targeting the inhibition of a yet to be determined ubiquitin ligase(s) that normally degrades PPAR $\beta$. For example, PPAR $\beta$ in cancer cells (HEK293 and NIH3T3) is ubiquitinated and degraded in a ligand (GW501516)-dependent manner [76]. While the identification of the ubiquitin ligase targeting PPAR $\beta$ is not known at this time, ubiquitin ligases degrading other isoforms (e.g. PPAR $\gamma$ ) have been reported in adipocytes (MKRN1) [77]. Conversely, MuRF2 ubiquitination could be enhancing a de-ubiquitinase (DUB) that prevents proteasome-mediated degradation by this unidentified E3(s).

We next sought to determine the underlying mechanism by which endogenous MuRF2 exerted inhibition on PPAR-regulated genes (Fig. 4). Based in the limited work performed on PPAR ubiquitination (as recently reviewed [43]), we hypothesized that the ratio of MuRF2 to the substrate may regulate whether the protein was degraded in a proteasome-dependent manner, as previously reported in cancer with MDM2:PPAR $\alpha$ ratios [73]. Increasing the MuRF2:PPAR $\gamma 1$ ratios resulted in a dose-dependent decrease in steady state protein levels, consistent with poly-ubiquitination and subsequent degradation (Fig. 6b). To determine the role of the proteasome in this process, we next repeated these experiments and found that the MuRF2-mediated decrease in PPAR $\gamma 1$ could be prevented by adding the proteasome inhibitor MG132 (Fig. 6d). Since previous studies have reported that ubiquitin ligase mediated proteasome degradation of PPARs is ligand dependent (as recently reviewed [43]), we next repeated these studies in the presence and absence of PPAR $\gamma$ ligand rosiglitazone, demonstrating that MuRF2's dose-dependent degradation of PPAR $\gamma 1$ was ligand dependent (Fig. 6d). To establish that MuRF2 interacts with PPAR $\gamma 1$, we performed immunoprecipitation studies by co-transfecting cells with HA-MuRF2 or HA-MuRF2 $\Delta$ Ring (lacking the ubiquitin ligase region) and FLAG-PPAR $\gamma 1$ (Fig. 6c). Immunoprecipitating $\operatorname{PPAR} \gamma 1$, we identified that MuRF2 bound PPAR $\gamma 1$ by immunoblots (Fig. 6c). Unexpectedly, MuRF2 $\Delta$ Ring did not bind PPAR $\gamma 1$ in parallel studies suggesting MuRF2's Ring Finger domain has structural importance in the interaction with PPAR $\gamma 1$.

In vivo, the cardiac MuRF2 protein levels increased $\sim 30 \%$ in wild type mice (Fig. 1c), while steady state levels of PPAR $\alpha$ PPAR $\beta$, and PPAR $\gamma 1$ were either increased (PPAR $\alpha, \operatorname{PPAR} \gamma 1)$ or unchanged (PPAR $\beta$ ) in wildtype mice in response to 26 weeks of high fat diet compared to chow-fed wildtype controls (Fig. 6a). With no evidence that cardiac MuRF2 affected steady state PPAR $\gamma 1$ isoform protein levels yet inhibited PPAR $\gamma 1$ activity in vivo (MuRF2-/- hearts had enhanced PPAR $\gamma 1$ activities), we next tested how MuRF2 may be inhibiting PPAR $\gamma 1$ mechanistically. Specifically, we wanted to determine why the physiological relevance of MuRF2-mediated degradation (with MuRF2:PPARg1 at levels 10:1) in vivo did not appear relevant in the context of diabetic cardiomyopathy. The experimental studies indicating that high MuRF2:PPAR $\gamma 1$ ratios resulted in ligand-dependent proteasome degradation may be relevant in other 


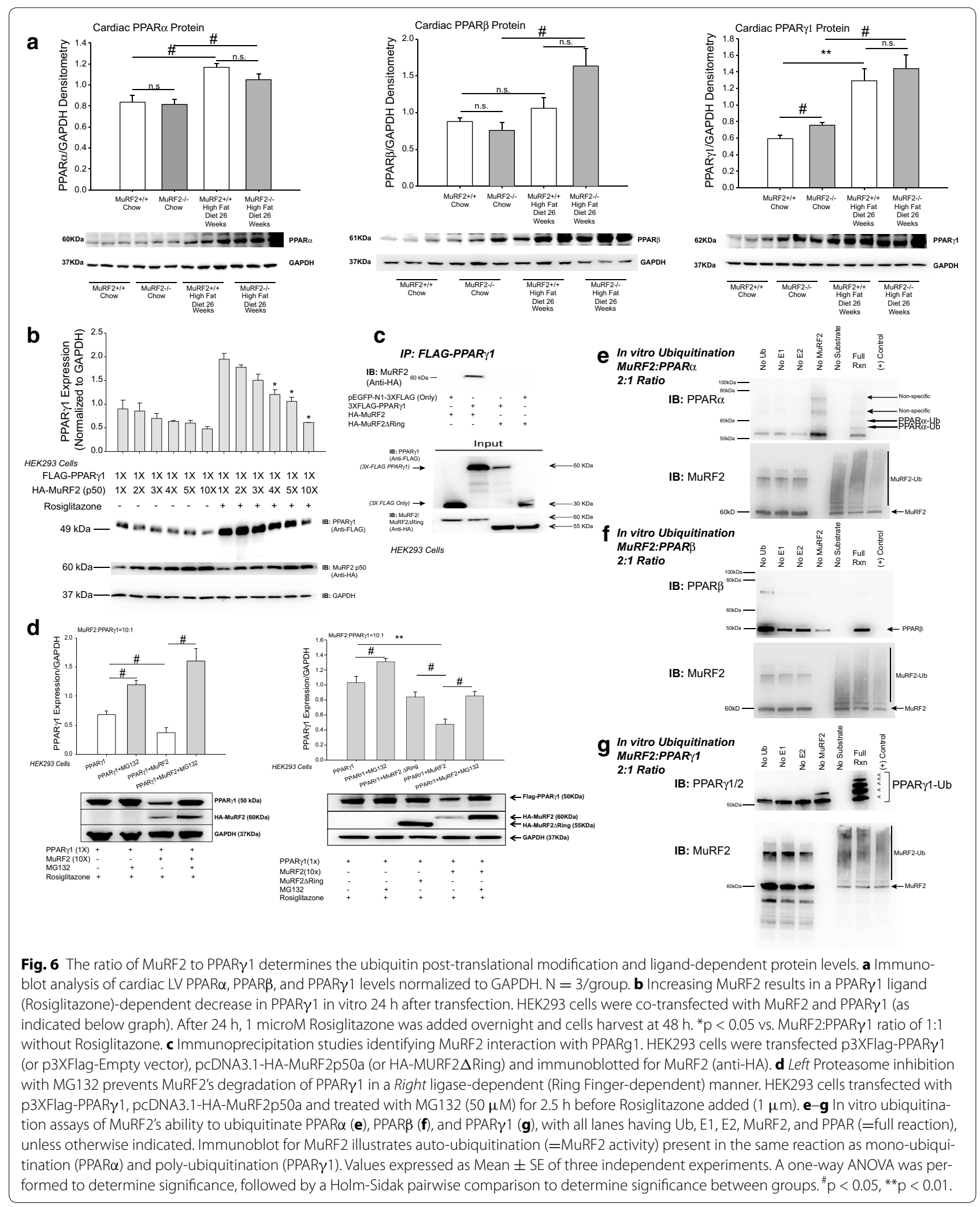


disease processes where MuRF2 levels are increased more in vivo. However, such a disease process has not been described to date. Therefore, we focused our studies of MuRF2-mediated ubiquitination of PPAR isoforms using ratios of 2:1 (Fig. 6e-g). Whereas, MuRF2 did not appear to add poly-ubiquitination leading to degradation, MuRF2 drove multi-mono-ubiquitination on PPAR $\alpha$ and PPAR $\gamma 1$. Specifically, MuRF2 di-monoubiquitinated PPAR $\alpha$, while adding $\sim$ four ubiquitin moieties to PPAR $\gamma 1$ (Fig. 6e, g, respectively). PPAR $\beta$, however, was unexpectedly not modified by ubiquitin at all in vitro. These studies add perspective to our initial findings that endogenous cardiac MuRF2 had the greatest regulation of PPAR $\gamma$, with MuRF2-/- hearts exhibiting $400 \%+$ PPAR $\gamma$ activity found in the sibling wildtype hearts (Fig. 1a, far right). Endogenous MuRF2 similarly had the next most inhibition of PPAR $\alpha$, with MuRF2-/hearts exhibiting $\sim 250 \%$ PPAR $\alpha$ activity found in sibling wildtype hearts (Fig. 1a, far left). Quite surprising was the finding that MuRF2 did not ubiquitinate PPAR $\beta$ (Fig. 6f), despite MuRF2 hearts exhibiting $80 \%$ more activity than wildtype controls (Fig. 1a, middle).

To gain more insight on how MuRF2 may be inhibiting transcriptional activity by ubiquitination, we next performed nuclear localization studies using confocal microscopy (Fig. 7). In control cells, we found that PPAR $\gamma 1$ could be found in both the nucleus and cytosol, with most cells having primarily nuclear localization (81\%) (Fig. 7a). Increasing MuRF2 (2:1 ratio of PPAR $\gamma 1$ transfected) interestingly resulted in an increase in the "perinuclear" localization of PPAR $\gamma 1$ (Fig. 7b). Notably, MuRF2 co-localized to these perinuclear regions (Fig. 7b). Parallel studies using the MuRF2 without its ubiquitin ligase activity ( $\triangle$ RING-MuRF2) abrogated the perinuclear targeting of PPAR $\gamma$ and colocalization with MuRF2 (Fig. 7c). Since we demonstrated that MuRF2, but not MuRF2 $\Delta$ Ring, bound to PPAR $\gamma 1$ (Fig. 6c), these studies indicates that MuRF2 regulation of PPAR $\gamma 1$ location may lie in its ubiquitin ligase activity and/or through some structural role required for interaction since MuRF2's Ring Finger domain is required to bind PPAR $\gamma 1$ (Fig. 6c). Taken together, these studies suggested that MuRF2 targets an ubiquitin-mediated regulation of PPAR $\gamma 1$ activity by altering its localization within the nucleus, paralleling recent studies demonstrating autophagic sequestration of receptors in the endoplasmic reticulum and nucleus [78].

By non-targeted metabolomics analysis, MuRF2 hearts had significant decreases in taurine, myoinositol, and four metabolites involved in malate-aspartate shuttle (glycerol-1phosphate, urea, malic acid, and phosphoric acid) [37]. In the present study, we similarly analyzed MuRF2-/- hearts using non-targeted metabolomics analysis after 26 weeks of high fat diet (Fig. 8). The separation of MuRF2-/- hearts from wildtype was clear using



Fig. 7 MuRF2 alters nuclear localization of PPAR 1 in a ubiquitin ligase region (RING)-dependent manner without altering steady state protein levels (as found in vivo). Increased MURF2 alters PPAR 1 localization from primarily nuclear a to increased cytosolic/perinuclear localization $\mathbf{b}$ in HL-1 cardiomyocyte-derived cells. MuRF2 lacking ubiquitin ligase activity ( $\triangle$ RING FingerMuRF2, c does not alter PPAR 1 localization compared controls (top row), indicating MuRF2's dependence on its ubiquitin ligase activity in mediating these changes. Representative of three biological replicates. Right Percentages based on the number of cells analyzed ( $N=58,68$, and 88 in FLAG-PPAR 1 , FLAG-PPAR $\gamma 1+$ HA-MuRF2, and FLAGPPAR $1+$ HA- $\triangle$ RING-MuRF2 groups, respectively). 
Principal Components Analysis (PCA) (Fig. 8a) as well as Partial Least Squares Discriminant Analysis (PLS-DA) and Variable Interdependent Parameters (VIP) analysis (Fig. 8b). Among all of the annotated metabolites (Fig. 8c), the VIP significant analytes detected were taurine, sucrose, glyceric acid, 3-hydroxyflavone, pantothenic acid, and glutamic acid, among others (Fig. 8b). Enrichment analysis identified the (1) urea cycle; (2) aspartate metabolism; and (3) taurine and hypotaurine metabolism to be the highest fold enriched by metabolite sets (Fig. 8d). Based on location, the mitochondria, peroxisome, and lysosome were the most enriched (Fig. 8e). Pathway analysis identified (1) taurine and Hypotaurine metabolism; (2) glycine, serine, and threonine metabolism; and (3) alanine, aspartate, and




glutamate metabolism as the pathways most significantly affected when both $t$ test and VIP significant metabolites were analyzed (Additional file 6: Figure S6).

\section{Discussion}

While the present study demonstrates a role for the muscle specific ubiquitin ligase in regulating PPAR transcription factors in the context of diabetes, the clinical implications of these findings are broader. Recent studies have identified reductions in MuRF2 in patients with diabetic ischemic heart failure (GEO ID: 87403976, http:// www.ncbi.nlm.nih.gov/geoprofiles?term $=87403976$ ). Rare MuRF2 mutations in patients with familial hypertrophic cardiomyopathy have also been identified that are associated with a greater $\mathrm{LV}$ wall thickness than those without MuRF2 mutations [79]. Genome wide identification of SARS-CoV susceptibility loci using the collaborative cross has identified MuRF2 as a susceptibility factor to SARS infection, including evidence that MuRF2-/mice are more susceptible (R.S. Baric, personal communication and GEO accession no. GSE64660, http://www. ncbi.nlm.nih.gov/geo/query/acc.cgi?acc=GSE64660). Taken together, these studies suggest a role for MuRF2 in an increased susceptibility to disease. Given the growing evidence that PPARs have anti-inflammatory activity by competitively inhibiting NF- $\kappa$ B and AP1 (cJun/cFos) experimentally (recently reviewed by Lockyer et al. [80]), it is possible that reduced (or ablated) MuRF2 in patients may increase their susceptibility to infection in addition to diabetes as we demonstrate in the present study.

The dynamic regulation of PPAR transcription factor activity reflects the complexity found routinely in biology. PPAR family transcription factors routinely partner with RXR to regulate transcription of target genes, but cofactors such as PGC-1a enhance PPAR activity (induced by exercise) and mitochondrial biogenesis, which nuclear receptor corepressor 1 (NCOR1) antagonizes these activity (as recently reviewed by Fan and Evans) [81]. PPAR activity is also regulated by ligands which bind the ligand binding domain and include endogenously free fatty acids, eicosinoids, and environmental compounds [82]. In addition to the various co-complex partners that regulate PPARs, there are other transcription factors that compete with PPARs to regulate their activity, notably NF- $\kappa B$, making enhanced PPAR activity an anti-inflammatory state [80]. It is on top of this complexity that post-translational modification by ubiquitin and SUMO has been reported primarily in cancer cells, and recently by our group in cardiomyocytes for the first time [83]. In our recent review on this topic, few ubiquitin ligases have been described, but ubiquitination and proteasome-dependent degradation of PPAR as well as SUMOylation has been reported in PPAR $\alpha$, PPAR $\beta$, and PPAR $\gamma 1$ in primarily non-physiological cultured conditions. The report here of the first ubiquitin ligase regulating PPAR $\gamma 1$ by ubiquitination in a physiological process and cardiac pathophysiological process (diabetes) adds detail to a dimension of regulation we've just begun to understand.

These layers of complexity are apparent in the present study. While our initial studies revealed that MuRF2-/hearts had enhanced PPAR $\alpha$, PPAR $\beta$, and PPAR $\gamma 1$ (most prominently PPAR $\gamma 1$ ) activity measured by binding of PPRE DNA (Fig. 1a). However, these enhanced activities were clearly not due to increased total protein levels of PPAR $\alpha$ and PPAR $\gamma 1$ (Fig. 6a). Similarly, PPAR $\alpha$ and PPAR $\gamma 1$ were multi-mono-ubiquitinated as a mechanism to explain their inhibition (Fig. 6e, g), while PPAR $\beta$ was not ubiquitinated by MuRF2 (Fig. 6f). Like previous studies from our laboratory, the nuclear localization after MuRF protein post-translational ubiquitination may be regulating this process with PPAR $\gamma 1$ (Fig. 7) [83]. However, the indirect regulation of PPAR $\beta$ protein levels (enhanced in MuRF2-/- hearts) is complex. The increase in PPAR $\beta$ protein levels is not transcriptionally regulated (Additional file 3: Figure S3b), leading to our hypothesis that MuRF2 regulates PPAR $\beta$ through complex post-translational mechanism(s) as described above (e.g. MuRF2 degradation of E3(s) targeting PPAR $\beta$ or MuRF2 enhancing DUBs targeting PPAR $\beta$ ). Similarly complexity may lie with MuRF2's regulation of PPAR $\alpha$ as PPAR $\alpha$ mRNA levels are enhanced in MuRF2-/- hearts throughout this study (Fig. 3a). The regulatory elements in the promoter region of PPAR include activator protein-1 (AP-1) and how MuRF2 may inhibit these proteins is not clear $[84,85]$. MuRF2-/ - mice have equivalent PPAR $\gamma 1$ protein (Fig. 6a) and PPAR $\gamma 1$ mRNA (Additional file 3: Figure S3c). However, MuRF2-/- hearts also have the most highly activated PPAR $\gamma 1$ activity by several measures (Figs. 1a, 4d), indicating that the strong post-translational multi-monoubiquitination in vitro (Fig. 6g) may be MuRF2's primary mechanism of regulating PPAR $\gamma 1$ in vivo.

MuRF2 has previously been shown to regulate two nuclear transcription factors found in myocytes, paralleling its role in regulating nuclear PPAR isoforms in the present study. Initial studies investigating the role of MuRF2 in differentiated myocytes identified that MuRF2 binds critical signaling regions of the giant protein titin (via titin kinase region), to interact and regulate the activity and localization of the nuclear transcription factor SRF [41]. However, cardiac MuRF2 did not appear to regulate SRF activity in vivo, when stimulated by known SRF activating pressure overload-induced cardiac hypertrophy [26], suggesting this regulation is disease context specific. Subsequently, MuRF2 has been implicated in redundantly regulating (with MuRF1) other nuclear transcription factors implicated in developmental 
physiological hypertrophy [40]. In both cases, no evidence of MuRF2-mediated degradation was identified, consistent with the degradation-independent regulation of PPAR isoforms in the present study. The most commonly reported regulation of PPAR isoforms from the cancer literature has identified that post-translational modification with ubiquitin and SUMO appears to regulate PPAR most commonly to inhibit their regulation.

The post-translational regulation of PPAR by ubiquitin has previously been identified in cancer cells. However, ubiquitin-regulation of PPARs in the heart has not. Similarly, specific ubiquitin ligases have not been identified in these processes prior to this identification of MuRF2. In contrast to prior studies where ubiquitination was ligand dependent and resulted in PPAR degradation (as recently reviewed [43]), here we identified that the MuRF2:PPAR $\gamma 1$ ratio determined if degradation occurred (Fig. 6b) and that the physiologically relevant non-degradation of PPAR $\alpha$, PPAR $\beta$, and PPAR $\gamma 1$ (Fig. 6a) resulted from multi-mono-ubiquitination of PPAR isoform substrates (Fig. 6e, g).

The ubiquitin ligase:substrate ratio effects on ubiquitination chain type has been studied extensively in cancer with MDM2's regulation of p53 [86-90]. In these series of elegant studies, investigators identified that low levels of MDM2 induced mono-ubiquitination and nuclear export of p53, whereas high levels of MDM2 promoted poly-ubiquitination and nuclear degradation of p53 [90]. In the context of stress, $\mathrm{Li}$ et al. endorsed the notion that non-stressed cells regulated p53 by mono-ubiquitination to circumvent the more extensive investment in energy the poly-ubiquitination and degradation require [89]. Conceptually, this increased energy expenditure may be worthwhile during stress considering that the bigger degradation response leads to apoptosis, whereas mono-ubiquitnation does not [89]. These studies also highlight the highly dynamic process of transcription factor regulation at the post-translational level [87]. Subsequent studies identified that SUMOylation, a process paralleling ubiquitination, can regulate the strength of the MDM2-p53 interaction and participates in the nuclear export [88]. This process appears to involve the stepwise interplay between SUMOylation and ubiquitination of p53 [86]. Very much like p53, all three PPAR isoforms are both SUMOylated and ubiquitinated, so future studies investigating the possible role of MuRF2regulation of PPAR isoform ubiquitination may take this into consideration. The requirement of SUMOylation for ubiquitination to occur may also explain MuRF2's apparent regulation of PPAR $\beta$ activity (Fig. 1a, middle frame) in vivo, but absence of PPAR $\beta$ ubiquitination in vitro (Fig. 6f) with demonstrable MuRF2 activity but lack of SUMO and/or other interacting proteins.
Another unexpected finding in the present study is the multi-mono-ubiquitination of PPAR $\alpha$ and PPAR $\gamma 1$ proteins identified in the in vitro ubiquitination assays (Fig. 6e, g, respectively). In cancer cells, the ubiquitin ligase 14ARF has been reported to di-ubiquitinate p53 in a manner which inhibits MDM2, another 14ARF substrate [91]. Like previous reports of multi-ubiquitinated (e.g. mono- and di-ubiquitination) substrates [92-94], di- or tri-ubiquitination of PPAR does not lead to its degradation in the physiological conditions. Interestingly, 14ARF induces p53-dependent SUMOylation in its target substrates, including MDM2 and NPM, in addition to ubiquitinating the protein [91]. MuRF2's multi-ubiquitination may offer additional clues into the complex regulation of cardiac PPAR isoforms previously unknown.

We previously identified that MuRF2-/- hearts exhibited alterations in taurine, aspartic acid, and d-malic acid in vivo compared to strain-matched wildtype hearts [37]. In the present study, we expanded these findings in MuRF2-/- hearts after 26 weeks high fat diet to illustrate that differences in taurine, sucrose, glyceric acid, 3-hydroxyflavone, pantothenic acid, and glutamic acid (Fig. 8b). Alternations in taurine and hypotaurine metabolite sets (Fig. 8d) in the MuRF2-/- hearts are interesting given the emerging role of taurine on chronic heart failure. Taurine is an abundant amino acid that influences the heart's response to stress. It is one of the most abundant amino acids in the left ventricle, acting as an osmoregulator to trigger osmotic preconditioning, a process that activates Akt-dependent cytoprotective signaling [95]. The loss of taurine can depress protein synthesis and reduce energy reserves after cardiac surgery and has been found to be preserved [96]. Specifically, taurine has been shown to attenuate oxidative stress and alleviate heart failure in diabetic rates [97]. Supplementation of taurine in patients with heart failure has been used clinically $[98,99]$. Our understanding of cardiac taurine biology is limited, but regulation of taurine by the taurine/ $\mathrm{Na}+$ symport is believed to play an important functional role in heart failure and replacement an emerging practice in Japan. It's role in diabetic cardiomyopathy, in particular, has been found to reduce AGE, oxidized LDL by scavenging malondialdehyde, and hypochlorous acid and downstream HClO-dependent NO reduction [100].

At least three ubiquitin ligases, namely RNF5, TRAF6, and Nedd4 have been described as regulators of autophagy components ATG4B and Beclin1 in non-cardiovascular systems [101]. With the growing appreciation of E3s in regulating autophagy and MuRF2's interactions with the autophagy-related Nbr1, p62, and LC3 proteins during cardiac myofibril assembly and turnover [41, 102], it was surprising that MuRF2-/- cardiac autophagy was not affected differentially after the high fat diet challenge 
(Additional file 5: Figure S5b). Despite these provocative parallels, no previous studies of MuRF2's regulation of autophagic flux have been described, and in the present studies, the lack of endogenous MuRF2 did not affect autophagic flux after high fat diet challenge (Additional file 5: Figure S5b). Similarly, steady state cardiac p62 protein levels were unaffected by the lack of endogenous MuRF2 (Additional file 5: Figure S5b), indicating that cardiac MuRF2 may not have a role in cardiac autophagy or that other MuRF family proteins, such as MuRF1 which has been described in multiple processes $[37,40]$, are functionally redundant and is compensating in the MuRF2-/- model. As emerging evidence that autophagy plays a role in the pathogenesis of diabetic cardiomyopathy by clearing post-translationally modified proteins, such as advanced glycation end products and the severity of disease [19], targeting autophagy may offer one therapeutic pathway [103]. In the present study, we did not identify that endogenous MuRF2 was protective via this pathway, however.

A host of changes have been described in diabetic cardiomyopathy, characterized by cardiac hypertrophy, inflammation, fibrosis, and apoptosis due to altered insulin signaling and calcium handling [104]. The MuRF family ubiquitin ligases, including MuRF1 and MuRF2 have shown to be critical regulators of cardiomyocyte growth and atrophy. Specifically, both physiological and pathological growth has been attributed to MuRF1 and MuRF2 in the heart [40, 46, 105] and skeletal muscle [106], while MuRF1 regulation of cardiac [106] and skeletal muscle atrophy $[107,108]$. While the changes seen in diabetic cardiomyopathy are vast, including alternations in metabolism, structural proteins, signal transduction, and ion channels [109], the crucial role of enhanced PPAR signaling has been central to the pathogenesis of this disease downstream of altered insulin resistance [12, 44]. Regulation of PPAR activity, including post-translational modification-mediated regulation, is a process little understood in any cell type, including the cardiomyocyte. The findings of the current study implicate the first cardiac specific ubiquitin ligase that functionally regulates PPAR isoform signaling, by ubiquitination, inhibiting a central pathway in the pathogenesis of disease. Since the regulation of PPARs are dynamic during the course of diabetic cardiomyopathy [110-113], these studies identify the role of MuRF2 in the pathogenesis of diabetic cardiomyopathy and its regulation of PPAR isoforms, including the post-translational inhibition of PPAR $\gamma 1$ that is cardioprotective in vivo.

\section{Conclusions}

We describe the first mechanism by which an ubiquitin ligase inhibits multiple cardiac PPAR isoforms, to protect against high fat diet-induced diabetic cardiomyopathy. We identified that MuRF2 protein levels increase $20 \%$ during the development of diabetic cardiomyopathy induced by high fat diet. Compared to littermate wildtype hearts, MuRF2-/ - hearts exhibit an exaggerated diabetic cardiomyopathy, characterized by an early onset systolic dysfunction, larger left ventricular mass, and higher heart weight. MuRF2-/- hearts had significantly increased PPAR $\alpha$ - and PPAR $\gamma 1$-regulated gene expression by RTqPCR, consistent with MuRF2's regulation of these transcription factors in vivo. Recent studies have described MuRF2 mutations to contribute to the severity of familial hypertrophic cardiomyopathy. The present study suggests that the lack of MuRF2 activity, as found in these patients, can result in an exaggerated diabetic cardiomyopathy. These present studies also identify MuRF2 as the first ubiquitin ligase to regulate cardiac PPAR $\alpha$ and PPAR $\gamma 1$ activities in vivo via post-translational modification without degradation and may represent a novel potential therapeutic target against heart failure in diabetes.

\section{Additional files}

\begin{abstract}
Additional file 1: Figure S1. Analysis of circulating total cholesterol, triglyceride, glucose, insulin, and muscle weight analysis at baseline and after 26 weeks high fat diet challenge. A. Fasting blood glucose and fasting serum insulin levels. B. Fasting total cholesterol and fasting serum triglyceride levels. C. Organ weights at 26 weeks high fat diet of gastrocnemius, soleus, and tibialis anterior. Values represent the mean \pm SE ( $N$ indicated above bars). Values expressed as Mean \pm SE. A one-way ANOVA was performed to determine significance followed by an all pairwise multiple comparison procedure (Holm-Sidak method). $\# p<0.05,{ }^{*} p<0.001$.
\end{abstract}

Additional file 2: Figure S2. Histological analysis of MuRF2-/- mice. A. Representative H\&E analysis of MuRF2-/- and MuRF $2+/+$ tissue. B. Single MuRF2+/+ heart from mouse found dead 21 weeks high fat diet reveals amorphous way infiltration (arrows) and rare leukocytes infiltrations $\left({ }^{*}\right)$. C. Analysis of Masson's Trichrome stained slides of MuRF2+/+ heart revealed $\sim 3 \%$ fibrosis.

Additional file 3: Figure S3. mRNA analysis of cardiac PPAR isoform expression in MuRF2 -/- mice. Quantitative RT qPCR analysis of cardiac $\mathbf{A}$. PPAR $\propto$ mRNA B. PPAR $\beta$ mRNA and C. PPAR $\gamma 1$ mRNA at baseline and 26 weeks after high fat diet compared to sibling-matched wild type hearts. $\mathrm{N}=5$ /group. A one-way ANOVA was performed to determine significance followed by an All Pairwise Multiple Comparison Procedure (Holm-Sidak method). ${ }^{*} p<0.001$

Additional file 4: Figure S4. Detection of cardiac O-GlcNac Protein modifications in MuRF2-/- mice after 26 weeks HFD challenge. A. Densitometric analysis of O-GlcNac/Bactin immunoblot (B). N=3/group. Values expressed as Mean $\pm \mathrm{SE}$. A one-way ANOVA was performed to determine significance followed by an All Pairwise Multiple Comparison Procedure (Holm-Sidak method). \#p $<0.05$.

Additional file 5: Figure S5. Analysis of MuRF2-/- cardiac NF-kB, IRS-1, cJun signaling and autophagy. A. Immunoblot analysis of NF-KB, IRS-1, and cJun reveal no differences in MuRF2-/- and sibling wild type mice ( $N=3$ / group). B. Analysis of autophagic flux post-Bafilomycin treatment prior to harvest did not detect differences in LC3II isoform, p62, or VPS34 protein levels. Values expressed as Mean \pm SE. Statistical analysis was performed using a Student's t-test. $N=3 /$ group. Significance determined as $p<0.05$.

Additional file 6: Figure S6. Pathway analysis of VIP and t-test significant metabolites found in non-targeted metabolomics analysis of MuRF2/- hearts after high fat diet. $N=3$ /group. 


\section{Abbreviations}

c-Jun: jun proto-oncogene; DAG: diacylglycerol; EF\%: ejection fraction \%; FOXO: forkhead box O; FS\%: fractional shortening \%; IKK: inhibitor кB kinase; IRS1: insulin receptor substrate-1; JNK: c-JUN NH 2-terminal kinase; LV: left ventricular; LV Vol: left ventricular volume; LVESD: left ventricular end systolic dimension; LVEDD: left ventricular end diastolic dimension; MDM2: mouse double minute 2 homolog (ubiquitin ligase); MuRF2: muscle ring finger-2; NFKB: nuclear factor kappa B; O-GICNAc: O-linked N-acetylglucosamine; p53: aka TP53-tumor protein 53; PPAR: peroxisome proliferator activating receptor; PCA: principal components analysis; PLS-DA: partial least squares discriminant analysis; PPRE: PPAR-response element; PKC: protein kinase C; SRF: serum response factor; VIP: variable interdependent parameters.

\section{Authors' contributions}

$J H, M Q$, and $M W$ conceived the experimental approach, coordinated and performed the animal experiments (husbandry, feeding, breeding, colony management) and wrote/edited the manuscript. JH, MQ performed western blots, blood collection and insulin analyses in addition to molecular in vitro tests. MW and MQ performed the echocardiography and harvested the tissues for metabolomics. JH, JS, and WS assisted with the design of the high fat diet and interpretation of the cardiac function and morphometric data. YH performed DNA genotyping of the mouse colony to confirm identification after harvesting and contributed to analysis and interpretation of molecular studies. TP carried out the experiments investigating autophagic flux. JS and TG performed and assisted $\mathrm{JH}$ and $\mathrm{MQ}$ with determining glycogen and triglyceride levels in skeletal muscle, liver, and heart. CY performed histological analysis of fibrosis and vimentin staining. RM and MFE designed the O-GIC-NAC studies, performed the immunoblots, and wrote the interpretation of the results. J, CN, and MM performed the non-targeted metabolomics studies and identified the peaks; MW performed the Metaboanalyst data analysis, presentation, and interpretation of the metabolomics results. BC created the MuRF2 constructs used in the studies and contributed to the design of the molecular experiments with MW and $\mathrm{JH}$, delineating the role of MuRF2 and PPAR $\gamma 1$ stability. All authors read and approved the final manuscript.

\section{Author details}

${ }^{1}$ Department of Pathology and Laboratory Medicine, University of North Carolina, 111 Mason Farm Road, MBRB 2340B, Chapel Hill, NC, USA. ${ }^{2}$ General Hospital of Ningxia Medical University, Yinchuan, Ningxia, People's Republic of China. ${ }^{3}$ Department of Surgery, University of North Carolina, Chapel Hill, NC, USA. ${ }^{4}$ Department of Biology, University of North Carolina, Chapel Hill, NC, USA. ${ }^{5}$ McAllister Heart Institute, University of North Carolina, 111 Mason Farm Road, MBRB 2340B, Chapel Hill, NC, USA. ${ }^{6}$ Department of Nutrition, University of North Carolina, Chapel Hill, NC, USA. ${ }^{7}$ Department of Pharmacology, University of North Carolina, Chapel Hill, NC, USA. ${ }^{8}$ Department of Internal Medicine (Cardiology), University of Texas Southwestern Medical Center, Dallas, TX, USA. ${ }^{9}$ Department of Health Promotions and Development, School of Nursing, University of Pittsburgh, Pittsburgh, PA, USA. ${ }^{10}$ Cardio-Metabolic Research Group (CMRG), Department of Physiological Sciences, Stellenbosch University, Stellenbosch 7600, South Africa. ${ }^{11}$ Sarah W. Stedman Nutrition and Metabolism Center, Duke Molecular Physiology Institute, Duke University Medical Center, Durham, NC, USA. ${ }^{12}$ Division of Endocrinology, Metabolism, and Nutrition, Department of Medicine, Duke University Medical Center, Durham, NC, USA. ${ }^{13}$ East Chapel Hill High School, Chapel Hill, NC, USA. ${ }^{14}$ Novartis, Novartis Institutes for BioMedical Research, Inc., 400 Technology Square, Boston, MA 601-4214, USA.

\section{Acknowledgements}

The authors wish to thank the UNC Animal Histopathology Laboratory for assistance in preparing histological specimens and Dr. Bob Bagnell for his support and guidance with the confocal microscopy studies. Lastly, we thank Dr. Hyung-Suk Kim of the UNC Animal Clinical Chemistry and Gene Expression Laboratories for his assistance in analyzing serum for triglyceride and cholesterol measurements. This work was supported by the National Institutes of Health (R01HL104129 to M.W.), the Jefferson-Pilot Corporation (Fellowship to M.W.), and the Leducq Foundation Transatlantic Networks of Excellence (to M.W.). MRI analyses of fat and body mass were supported by the UNC Nutrition Obesity Research Center (DK056350). Proof reading and editing provided by Dr. Ashley G. Rivenbark.

\section{Compliance with ethical guidelines}

\section{Competing interests}

The authors declare that they have no competing interests.

Received: 25 March 2015 Accepted: 30 June 2015

Published online: 05 August 2015

\section{References}

1. Murray CJ, Lopez AD (1997) Mortality by cause for eight regions of the world: global burden of disease study. Lancet 349(9061):1269-1276

2. Bauters C, Lamblin N, Mc Fadden EP, Van Belle E, Millaire A, de Groote P (2003) Influence of diabetes mellitus on heart failure risk and outcome. Cardiovasc Diabetol 2:1

3. Simonson DC (1988) Etiology and prevalence of hypertension in diabetic patients. Diabetes Care 11(10):821-827

4. Poornima IG, Parikh P, Shannon RP (2006) Diabetic cardiomyopathy: the search for a unifying hypothesis. Circ Res 98(5):596-605

5. Yang Q, Li Y (2007) Roles of PPARs on regulating myocardial energy and lipid homeostasis. J Mol Med (Berl) 85(7):697-706

6. Buchanan J, Mazumder PK, Hu P, Chakrabarti G, Roberts MW, Yun UJ et al (2005) Reduced cardiac efficiency and altered substrate metabolism precedes the onset of hyperglycemia and contractile dysfunction in two mouse models of insulin resistance and obesity. Endocrinology 146(12):5341-5349

7. Aguiari P, Leo S, Zavan B, Vindigni V, Rimessi A, Bianchi Ket al (2008) High glucose induces adipogenic differentiation of muscle-derived stem cells. Proc Natl Acad Sci USA 105(4):1226-1231

8. Feige JN, Gelman L, Michalik L, Desvergne B, Wahli W (2006) From molecular action to physiological outputs: peroxisome proliferator-activated receptors are nuclear receptors at the crossroads of key cellular functions. Prog Lipid Res 45(2):120-159

9. Madrazo JA, Kelly DP (2008) The PPAR trio: regulators of myocardial energy metabolism in health and disease. J Mol Cell Cardiol 44(6):968-975

10. Doehner W, Rauchhaus M, Ponikowski P, Godsland IF, von Haehling S, Okonko DO et al (2005) Impaired insulin sensitivity as an independent risk factor for mortality in patients with stable chronic heart failure. J Am Coll Cardiol 46(6):1019-1026

11. Carley AN, Severson DL (2005) Fatty acid metabolism is enhanced in type 2 diabetic hearts. Biochim Biophys Acta 1734(2):112-126

12. Dirkx E, Schwenk RW, Glatz JF, Luiken JJ, van Eys GJ (2011) High fat diet induced diabetic cardiomyopathy. Prostaglandins Leukot Essent Fatty Acids 85(5):219-225

13. Yu C, Chen Y, Cline GW, Zhang D, Zong H, Wang Y et al (2002) Mechanism by which fatty acids inhibit insulin activation of insulin receptor substrate-1 (IRS-1)-associated phosphatidylinositol 3-kinase activity in muscle. J Biol Chem 277(52):50230-50236

14. Nishida M, Maruyama Y, Tanaka R, Kontani K, Nagao T, Kurose H (2000) $\mathrm{G}$ alpha(i) and $\mathrm{G}$ alpha(o) are target proteins of reactive oxygen species. Nature 408(6811):492-495

15. Molkentin JD (2004) Calcineurin-NFAT signaling regulates the cardiac hypertrophic response in coordination with the MAPKs. Cardiovasc Res 63(3):467-475

16. Puthanveetil P, Wan A, Rodrigues B (2013) FoxO1 is crucial for sustaining cardiomyocyte metabolism and cell survival. Cardiovasc Res 97(3):393-403

17. Fang CX, Dong F, Thomas DP, Ma H, He L, Ren J (2008) Hypertrophic cardiomyopathy in high-fat diet-induced obesity: role of suppression of forkhead transcription factor and atrophy gene transcription. Am J Physiol Heart Circ Physiol 295(3):H1206-H1215

18. Hirotani S, Otsu K, Nishida K, Higuchi Y, Morita T, Nakayama H et al (2002) Involvement of nuclear factor-kappaB and apoptosis signalregulating kinase 1 in G-protein-coupled receptor agonist-induced cardiomyocyte hypertrophy. Circulation 105(4):509-515

19. Varga ZV, Giricz Z, Liaudet L, Hasko G, Ferdinandy P, Pacher P (2015) Interplay of oxidative, nitrosative/nitrative stress, inflammation, cell 
death and autophagy in diabetic cardiomyopathy. Biochim Biophys Acta 1852(2):232-242

20. Centner T, Yano J, Kimura E, McElhinny AS, Pelin K, Witt CC et al (2001) Identification of muscle specific ring finger proteins as potential regulators of the titin kinase domain. J Mol Biol 306(4):717-726

21. Pizon V, lakovenko A, Van Der Ven PF, Kelly R, Fatu C, Furst DO et al (2002) Transient association of titin and myosin with microtubules in nascent myofibrils directed by the MURF2 RING-finger protein. J Cell Sci 115(Pt 23):4469-4482

22. McElhinny AS, Perry CN, Witt CC, Labeit S, Gregorio CC (2004) Musclespecific RING finger-2 (MURF-2) is important for microtubule, intermediate filament and sarcomeric M-line maintenance in striated muscle development. J Cell Sci 117(Pt 15):3175-3188

23. Perera S, Mankoo B, Gautel M (2012) Developmental regulation of MURF E3 ubiquitin ligases in skeletal muscle. J Muscle Res Cell Motil 33(2):107-122

24. Battiprolu PK, Hojayev B, Jiang N, Wang ZV, Luo X, Iglewski M et al (2012) Metabolic stress-induced activation of FoxO1 triggers diabetic cardiomyopathy in mice. J Clin Invest 122(3):1109-1118

25. Ni YG, Wang N, Cao DJ, Sachan N, Morris DJ, Gerard RD et al (2007) FoxO transcription factors activate Akt and attenuate insulin signaling in heart by inhibiting protein phosphatases. Proc Natl Acad Sci USA 104(51):20517-20522

26. Willis MS, Ike C, Li L, Wang DZ, Glass DJ, Patterson C (2007) Muscle ring finger 1 , but not muscle ring finger 2 , regulates cardiac hypertrophy in vivo. Circ Res 100(4):456-459

27. Makowski L, Zhou C, Zhong Y, Kuan PF, Fan C, Sampey BP et al (2014) Obesity increases tumor aggressiveness in a genetically engineered mouse model of serous ovarian cancer. Gynecol Oncol 133(1):90-97

28. Vaitheesvaran B, LeRoith D, Kurland IJ (2010) MKR mice have increased dynamic glucose disposal despite metabolic inflexibility, and hepatic and peripheral insulin insensitivity. Diabetologia 53(10):2224-2232

29. Xin-Long C, Zhao-Fan X, Dao-Feng B, Jian-Guang T, Duo W (2007) Insulin resistance following thermal injury: an animal study. Burns 33(4):480-483

30. Li LO, Ellis JM, Paich HA, Wang S, Gong N, Altshuller G et al (2009) Liverspecific loss of long chain acyl-CoA synthetase-1 decreases triacylglycerol synthesis and beta-oxidation and alters phospholipid fatty acid composition. J Biol Chem 284(41):27816-27826

31. Furuichi Y, Goto-Inoue N, Manabe Y, Setou M, Masuda K, Fujii NL (2014) Imaging mass spectrometry reveals fiber-specific distribution of acetylcarnitine and contraction-induced carnitine dynamics in rat skeletal muscles. Biochim Biophys Acta 1837(10):1699-1706

32. Mapanga RF, Rajamani U, Dlamini N, Zungu-Edmondson M, Kelly-Laubscher R, Shafiullah M et al (2012) Oleanolic Acid: a novel cardioprotective agent that blunts hyperglycemia-induced contractile dysfunction. PLoS One 7(10):e47322

33. Roessner U, Wagner C, Kopka J, Trethewey RN, Willmitzer L (2000) Technical advance: simultaneous analysis of metabolites in potato tuber by gas chromatography-mass spectrometry. Plant J 23(1):131-142

34. Fiehn O, Wohlgemuth G, Scholz M, Kind T, Lee do Y, Lu Y et al (2008) Quality control for plant metabolomics: reporting MSI-compliant studies. Plant J 53(4):691-704

35. Kind T, Wohlgemuth G, Leedo Y, Lu Y, Palazoglu M, Shahbaz S et al (2009) FiehnLib: mass spectral and retention index libraries for metabolomics based on quadrupole and time-of-flight gas chromatography/ mass spectrometry. Anal Chem 81(24):10038-10048

36. Banerjee R, Bultman SJ, Holley D, Hillhouse C, Bain JR, Newgard CB et al (2015) Non-targeted metabolomics of Brg1/Brm double-mutant cardiomyocytes reveals a novel role for SWI/SNF complexes in metabolic homeostasis. Metabolomics (in press)

37. Banerjee R, He J, Spaniel C, Quintana MT, Wang Z, Bain JR et al (2015) Non-targeted metabolomics analysis of cardiac Muscle Ring Finger-1 (MuRF1), MuRF2, and MuRF3 in vivo reveals novel and redundant metabolic changes. Metabolomics 11:312-322

38. Xia J, Mandal R, Sinelnikov IV, Broadhurst D, Wishart DS (2012) MetaboAnalyst 2.0-a comprehensive server for metabolomic data analysis. Nucleic Acids Res 40(Web Server issue):W127-W133

39. Xia J, Psychogios N, Young N, Wishart DS (2009) MetaboAnalyst: a web server for metabolomic data analysis and interpretation. Nucleic Acids Res 37(Web Server issue):W652-W660
40. Willis MS, Wadosky KM, Rodriguez JE, Schisler JC, Lockyer P, Hilliard EG et al (2014) Muscle ring finger 1 and muscle ring finger 2 are necessary but functionally redundant during developmental cardiac growth and regulate E2F1-mediated gene expression in vivo. Cell Biochem Funct 32(1):39-50

41. Lange $S$, Xiang F, Yakovenko A, Vihola A, Hackman P, Rostkova E et al (2005) The kinase domain of titin controls muscle gene expression and protein turnover. Science 308(5728):1599-1603

42. Ravingerova T, Adameova A, Carnicka S, Nemcekova M, Kelly T, Matejikova J et al (2011) The role of PPAR in myocardial response to ischemia in normal and diseased heart. Gen Physiol Biophys 30(4):329-341

43. Wadosky KM, Willis MS (2012) The story so far: post-translational regulation of peroxisome proliferator-activated receptors by ubiquitination and SUMOylation. Am J Physiol Heart Circ Physiol 302(3):H515-H526

44. Lee TI, Kao YH, Chen YC, Huang JH, Hsiao FC, Chen YJ (2013) Peroxisome proliferator-activated receptors modulate cardiac dysfunction in diabetic cardiomyopathy. Diabetes Res Clin Pract 100(3):330-339

45. How OJ, Aasum E, Severson DL, Chan WY, Essop MF, Larsen TS (2006) Increased myocardial oxygen consumption reduces cardiac efficiency in diabetic mice. Diabetes 55(2):466-473

46. Willis MS, Schisler JC, Li L, Rodriguez JE, Hilliard EG, Charles PC et al (2009) Cardiac muscle ring finger-1 increases susceptibility to heart failure in vivo. Circ Res 105(1):80-88

47. Aragno M, Mastrocola R, Medana C, Catalano MG, Vercellinatto I, Danni O et al (2006) Oxidative stress-dependent impairment of cardiacspecific transcription factors in experimental diabetes. Endocrinology 147(12):5967-5974

48. Liu X, Liu C, Zhang X, Zhao J, Xu J (2015) Urocortin ameliorates diabetic cardiomyopathy in rats via the Akt/GSK-3beta signaling pathway. Exp Ther Med 9(3):667-674

49. Li J, Peng L, Du H, Wang Y, Lu B, Xu Y et al (2014) The protective effect of beraprost sodium on diabetic cardiomyopathy through the inhibition of the p38 MAPK signaling pathway in high-fat-induced SD rats. Int J Endocrinol 2014:901437

50. Asbun J, Villarreal FJ (2006) The pathogenesis of myocardial fibrosis in the setting of diabetic cardiomyopathy. J Am Coll Cardiol 47(4):693-700

51. Factor SM, Minase T, Bhan R, Wolinsky H, Sonnenblick EH (1983) Hypertensive diabetic cardiomyopathy in the rat: ultrastructural features. Virchows Arch A Pathol Anat Histopathol 398(3):305-317

52. Van Linthout S, Seeland U, Riad A, Eckhardt O, Hohl M, Dhayat $\mathrm{N}$ et al (2008) Reduced MMP-2 activity contributes to cardiac fibrosis in experimental diabetic cardiomyopathy. Basic Res Cardiol 103(4):319-327

53. Aguilar H, Fricovsky E, Ihm S, Schimke M, Maya-Ramos L, Aroonsakool N et al (2014) Role for high-glucose-induced protein O-GlcNAcylation in stimulating cardiac fibroblast collagen synthesis. Am J Physiol Cell Physiol 306(9):C794-C804

54. Burkart EM, Sambandam N, Han X, Gross RW, Courtois M, Gierasch CM et al (2007) Nuclear receptors PPARbeta/delta and PPARalpha direct distinct metabolic regulatory programs in the mouse heart. J Clin Invest 117(12):3930-3939

55. Son NH, Park TS, Yamashita H, Yokoyama M, Huggins LA, Okajima K et al (2007) Cardiomyocyte expression of PPARgamma leads to cardiac dysfunction in mice. J Clin Invest 117(10):2791-2801

56. Liu S, Hatano B, Zhao M, Yen CC, Kang K, Reilly SM et al (2011) Role of peroxisome proliferator-activated receptor delta\}/\{beta in hepatic metabolic regulation. J Biol Chem 286(2):1237-1247

57. Okere IC, Chandler MP, MCElfresh TA, Rennison JH, Sharov V, Sabbah HN et al (2006) Differential effects of saturated and unsaturated fatty acid diets on cardiomyocyte apoptosis, adipose distribution, and serum leptin. Am J Physiol Heart Circ Physiol 291(1):H38-H44

58. Wang H, Sreenivasan U, Hu H, Saladino A, Polster BM, Lund LM et al (2011) Perilipin 5, a lipid droplet-associated protein, provides physical and metabolic linkage to mitochondria. J Lipid Res 52(12):2159-2168

59. Son $\mathrm{NH}$, Yu S, Tuinei J, Arai $\mathrm{K}$, Hamai H, Homma S et al (2010) PPARgamma-induced cardiolipotoxicity in mice is ameliorated by PPARalpha deficiency despite increases in fatty acid oxidation. J Clin Invest 120(10):3443-3454

60. Stanley WC, Recchia FA (2010) Lipotoxicity and the development of heart failure: moving from mouse to man. Cell Metab 12(6):555-556

61. Reichelt ME, Mellor KM, Curl CL, Stapleton D, Delbridge LM (2013) Myocardial glycophagy_a specific glycogen handling response to 
metabolic stress is accentuated in the female heart. J Mol Cell Cardiol 65:67-75

62. Wu Z, Chen Q, Ke D, Li G, Deng W (2014) Emodin protects against diabetic cardiomyopathy by regulating the AKT/GSK-3beta signaling pathway in the rat model. Molecules 19(9):14782-14793

63. Hemmeryckx B, Hoylaerts MF, Gallacher DJ, Rong Lu H, Himmelreich U, D'Hooge J et al (2013) Does rosiglitazone affect adiposity and cardiac function in genetic diabetic mice? Eur J Pharmacol 700(1-3):23-31

64. Hemmeryckx B, Gaekens M, Gallacher DJ, Lu HR, Lijnen HR (2013) Effect of rosiglitazone on liver structure and function in genetically diabetic Akita mice. Basic Clin Pharmacol Toxicol 113(5):353-360

65. Marsh SA, Powell PC, Dell'italia LJ, Chatham JC (2013) Cardiac O-GlcNAcylation blunts autophagic signaling in the diabetic heart. Life Sci 92(11):648-656

66. Kim HS, Woo JS, Joo HJ, Moon WK (2012) Cardiac transcription factor Nkx2.5 is downregulated under excessive O-GlcNAcylation condition. PLoS One 7(6):e38053

67. Ruan HB, Nie Y, Yang X (2013) Regulation of protein degradation by O-GlcNAcylation: crosstalk with ubiquitination. Mol Cell Proteomics 12(12):3489-3497

68. Yokoe S, Asahi M, Takeda T, Otsu K, Taniguchi N, Miyoshi E et al (2010) Inhibition of phospholamban phosphorylation by O-GlcNAcylation: implications for diabetic cardiomyopathy. Glycobiology 20(10):1217-1226

69. Clark RJ, McDonough PM, Swanson E, Trost SU, Suzuki M, Fukuda M et al (2003) Diabetes and the accompanying hyperglycemia impairs cardiomyocyte calcium cycling through increased nuclear O-GlcNAcylation. J Biol Chem 278(45):44230-44237

70. Ouwens DM, Boer C, Fodor M, de Galan P, Heine RJ, Maassen JA et al (2005) Cardiac dysfunction induced by high-fat diet is associated with altered myocardial insulin signalling in rats. Diabetologia 48(6):1229-1237

71. Thomas CM, Yong QC, Rosa RM, Seqqat R, Gopal S, Casarini DE et al (2014) Cardiac-specific suppression of NF-kappaB signaling prevents diabetic cardiomyopathy via inhibition of the renin-angiotensin system. Am J Physiol Heart Circ Physiol 307(7):H1036-H1045

72. Qi Y, Zhu Q, Zhang K, Thomas C, Wu Y, Kumar R et al (2015) Activation of Foxo1 by insulin resistance promotes cardiac dysfunction and betamyosin heavy chain gene expression. Circ Heart Fail 8(1):198-208

73. Genini D, Catapano CV (2007) Block of nuclear receptor ubiquitination. A mechanism of ligand-dependent control of peroxisome proliferatoractivated receptor delta activity. J Biol Chem 282(16):11776-11785

74. Witt SH, Granzier H, Witt CC, Labeit S (2005) MURF-1 and MURF-2 target a specific subset of myofibrillar proteins redundantly: towards understanding MURF-dependent muscle ubiquitination. J Mol Biol 350(4):713-722

75. Willis MS, Bevilacqua A, Pulinilkunnil T, Kienesberger P, Tannu M, Patterson C (2014) The role of ubiquitin ligases in cardiac disease. J Mol Cell Cardiol 71:43-53

76. Rieck M, Wedeken L, Muller-Brusselbach S, Meissner W, Muller R (2007) Expression level and agonist-binding affect the turnover, ubiquitination and complex formation of peroxisome proliferator activated receptor beta. FEBS J 274(19):5068-5076

77. Kim JH, Park KW, Lee EW, Jang WS, Seo J, Shin S et al (2014) Suppression of PPARgamma through MKRN1-mediated ubiquitination and degradation prevents adipocyte differentiation. Cell Death Differ 21(4):594-603

78. Mochida K, Oikawa Y, Kimura Y, Kirisako H, Hirano H, Ohsumi Y et al (2015) Receptor-mediated selective autophagy degrades the endoplasmic reticulum and the nucleus. Nature 522(7556):359-362

79. Su M, Wang J, Kang L, Wang Y, Zou Y, Feng X et al (2014) Rare variants in genes encoding MuRF1 and MuRF2 are modifiers of hypertrophic cardiomyopathy. Int J Mol Sci 15(6):9302-9313

80. Lockyer P, Schisler JC, Patterson C, Willis MS (2010) Minireview: Won't get fooled again: the nonmetabolic roles of peroxisome proliferator-activated receptors (PPARs) in the heart. Mol Endocrinol 24(6):1111-1119

81. Fan W, Evans R (2015) PPARs and ERRs: molecular mediators of mitochondrial metabolism. Curr Opin Cell Biol 33:49-54

82. Delfosse V, Maire AL, Balaguer P, Bourguet W (2014) A structural perspective on nuclear receptors as targets of environmental compounds. Acta Pharmacol Sin. doi:10.1038/aps.2014.133 [Epub ahead of print]
83. Rodríguez JE, Liao J, He J, Schisler JC, Newgard CB, Drujan D et al (2015) The ubiquitin ligase MuRF1 regulates PPAR $\alpha$ activity in the heart by enhancing nuclear export via monoubiquitination. Mol Cell Endocrinol (in press)

84. Fu M, Zhang J, Lin Y, Zhu X, Zhao L, Ahmad M et al (2003) Early stimulation and late inhibition of peroxisome proliferator-activated receptor gamma (PPAR gamma) gene expression by transforming growth factor beta in human aortic smooth muscle cells: role of early growthresponse factor-1 (Egr-1), activator protein 1 (AP1) and Smads. Biochem J 370(Pt 3):1019-1025

85. Jiang X, Yang X, Han Y, Lu S (2013) Transcription factor AP1 binds the functional region of the promoter and regulates gene expression of human PPARdelta in LoVo cell. Tumour Biol 34(6):3619-3625

86. Nie L, Sasaki M, Maki CG (2007) Regulation of p53 nuclear export through sequential changes in conformation and ubiquitination. J Biol Chem 282(19):14616-14625

87. Brooks CL, Li M, Gu W (2004) Monoubiquitination: the signal for p53 nuclear export? Cell Cycle 3(4):436-438

88. Carter S, Bischof O, Dejean A, Vousden KH (2007) C-terminal modifications regulate MDM2 dissociation and nuclear export of p53. Nat Cell Biol 9(4):428-435

89. Shmueli A, Oren M (2004) Regulation of p53 by Mdm2: fate is in the numbers. Mol Cell 13(1):4-5

90. Li M, Brooks CL, Wu-Baer F, Chen D, Baer R, Gu W (2003) Mono- versus polyubiquitination: differential control of p53 fate by Mdm2. Science 302(5652):1972-1975

91. den Besten W, Kuo ML, Tago K, Williams RT, Sherr CJ (2006) Ubiquitination of, and sumoylation by, the Arf tumor suppressor. Isr Med Assoc J 8(4):249-251

92. Thrower JS, Hoffman L, Rechsteiner M, Pickart CM (2000) Recognition of the polyubiquitin proteolytic signal. EMBO J 19(1):94-102

93. Buchberger A (2002) From UBA to UBX: new words in the ubiquitin vocabulary. Trends Cell Biol 12(5):216-221

94. Jackman RW, Kandarian SC (2004) The molecular basis of skeletal muscle atrophy. Am J Physiol Cell Physiol 287(4):C834-C843

95. Schaffer SW, Jong CJ, Ito T, Azuma J (2014) Effect of taurine on ischemia-reperfusion injury. Amino Acids 46(1):21-30

96. Spichtin H, Mihatsch MJ (1979) Diagnostic progress in familial nephropathy. Alport's syndrome, nail-patella syndrome and benign familial hematuria (author's transl). Pathol Res Pract 164(1):80-86

97. Wang GG, Li W, Lu XH, Zhao X, Xu L (2013) Taurine attenuates oxidative stress and alleviates cardiac failure in type I diabetic rats. Croat Med $J$ 54(2):171-179

98. Beyranvand MR, Khalafi MK, Roshan VD, Choobineh S, Parsa SA, Piranfar MA (2011) Effect of taurine supplementation on exercise capacity of patients with heart failure. J Cardiol 57(3):333-337

99. Ito T, Schaffer S, Azuma J (2014) The effect of taurine on chronic heart failure: actions of taurine against catecholamine and angiotensin II. Amino Acids 46(1):111-119

100. Ito T, Schaffer SW, Azuma J (2012) The potential usefulness of taurine on diabetes mellitus and its complications. Amino Acids 42(5):1529-1539

101. Kuang E, Qi J, Ronai Z (2013) Emerging roles of E3 ubiquitin ligases in autophagy. Trends Biochem Sci 38(9):453-460

102. Perera S, Holt MR, Mankoo BS, Gautel M (2011) Developmental regulation of MURF ubiquitin ligases and autophagy proteins nbr1, p62/ SQSTM1 and LC3 during cardiac myofibril assembly and turnover. Dev Biol 351(1):46-61

103. Wang B, Yang Q, Sun YY, Xing YF, Wang YB, Lu XT et al (2014) Resveratrol-enhanced autophagic flux ameliorates myocardial oxidative stress injury in diabetic mice. J Cell Mol Med 18(8):1599-1611

104. Fuentes-Antras J, Picatoste B, Gomez-Hernandez A, Egido J, Tunon J, Lorenzo O (2015) Updating experimental models of diabetic cardiomyopathy. J Diabetes Res 2015:656795

105. Wadosky KM, Rodriguez JE, Hite RL, Min JN, Walton BL, Willis MS (2014) Muscle RING finger-1 attenuates IGF-I-dependent cardiomyocyte hypertrophy by inhibiting JNK signaling. Am J Physiol Endocrinol Metab 306(7):E723-E739

106. Cohen S, Lee D, Zhai B, Gygi SP, Goldberg AL (2014) Trim32 reduces $\mathrm{PI3K}-\mathrm{Akt}-\mathrm{FoxO}$ signaling in muscle atrophy by promoting plakoglobinPI3K dissociation. J Cell Biol 204(5):747-758 
107. Bodine SC, Latres E, Baumhueter S, Lai VK, Nunez L, Clarke BA et al (2001) Identification of ubiquitin ligases required for skeletal muscle atrophy. Science 294(5547):1704-1708

108. Clarke BA, Drujan D, Willis MS, Murphy LO, Corpina RA, Burova E et al (2007) The E3 Ligase MuRF1 degrades myosin heavy chain protein in dexamethasone-treated skeletal muscle. Cell Metab 6(5):376-385

109. Sarkozy M, Zvara A, Gyemant N, Fekete V, Kocsis GF, Pipis J et al (2013) Metabolic syndrome influences cardiac gene expression pattern at the transcript level in male ZDF rats. Cardiovasc Diabetol 12:16

110. Lee TI, Kao YH, Chen YC, Pan NH, Chen YJ (2010) Oxidative stress and inflammation modulate peroxisome proliferator-activated receptors with regional discrepancy in diabetic heart. Eur J Clin Invest 40(8):692-699
111. Spiegelman BM (1998) PPAR-gamma: adipogenic regulator and thiazolidinedione receptor. Diabetes 47(4):507-514

112. Lee TI, Kao YH, Chen YC, Pan NH, Lin YK, Chen YJ (2011) Cardiac peroxisome-proliferator-activated receptor expression in hypertension co-existing with diabetes. Clin Sci (Lond) 121(7):305-312

113. Yu BC, Chang CK, Ou HY, Cheng KC, Cheng JT (2008) Decrease of peroxisome proliferator-activated receptor delta expression in cardiomyopathy of streptozotocin-induced diabetic rats. Cardiovasc Res 80(1):78-87

\section{Submit your next manuscript to BioMed Central} and take full advantage of:

- Convenient online submission

- Thorough peer review

- No space constraints or color figure charges

- Immediate publication on acceptance

- Inclusion in PubMed, CAS, Scopus and Google Scholar

- Research which is freely available for redistribution

Submit your manuscript at

www.biomedcentral.com/submit

() BioMed Central 